Research paper

\title{
Inhibition of adherence of the yeast Candida albicans to buccal epithelial cells by synthetic aromatic glycoconjugates
}

\author{
Harlei Martin a, Mairead Mc Govern b, Lorna Abbey a , Aisling Gilroy ${ }^{\mathrm{b}}$, Stephanie Mullins ${ }^{\mathrm{b}}$, \\ Sarah Howell ${ }^{\text {b }}$, Kevin Kavanagh ${ }^{\text {b, }}{ }^{*}$, Trinidad Velasco-Torrijos ${ }^{\text {a, }}$, \\ a Department of Chemistry, Maynooth University, Maynooth, Co. Kildare, Ireland \\ ${ }^{\mathrm{b}}$ Department of Biology, Maynooth University, Maynooth, Co. Kildare, Ireland
}

\section{A R T I C L E I N F O}

\section{Article history:}

Received 24 April 2018

Received in revised form

19 September 2018

Accepted 5 October 2018

Available online 9 October 2018

\section{Keywords:}

Candida albicans

Anti-Adherence

Multivalent glycoconjugates

Structure-activity relationship study

Copper-catalyzed azide-alkyne

cycloaddition (CuAAC)

\begin{abstract}
A B S T R A C T
The yeast Candida albicans is an opportunistic fungal pathogen which induces superficial and systemic infections in immunocompromised patients. Adherence to host tissue is critical to its ability to colonise and infect the host. The work presented here describes the synthesis of a small library of aromatic glycoconjugates (AGCs) and their evaluation as inhibitors of $C$. albicans adherence to exfoliated buccal epithelial cells (BECs). We identified a divalent galactoside, ligand $\mathbf{2 a}$, capable of displacing over $50 \%$ of yeast cells already attached to the BECs. Fluorescence imaging indicates that $\mathbf{2 a}$ may bind to structural components of the fungal cell wall.
\end{abstract}

(c) 2018 Elsevier Masson SAS. All rights reserved.

\section{Introduction}

The attachment of pathogenic microorganisms to the surface of the host cells is a prequisite for infection [1,2]. The mechanisms that mediate pathogen adherence often involve microbial proteins, known as adhesins, that recognise cell surface biomolecules such as protein receptors and glycans [3]. The development of compounds capable of blocking the adherence of pathogens to host cells is an attractive alternative to traditional antibiotic treatments that rely solely on killing the infective microorganisms [4,5]. There are several examples in which the anti-adherence approach has been exploited successfully to design inhibitors of microbial adherence [6]. Some of these include glycoclusters capable of preventing lung infection caused by Pseudomonas aeruginosa [7] and glycoconjugates used in the treatment of conditions caused by pathogenic strains of Escherichia coli, such as Crohn's disease [8] and urinary tract infections $[9,10]$. The lectins involved in the adherence processes in these reports (Lec A and Lec B from $P$. auroginosa and

\footnotetext{
* Corresponding author.

** Corresponding author

E-mail addresses: Kevin.Kavanagh@mu.ie (K. Kavanagh), trinidad. velascotorrijos@mu.ie (T. Velasco-Torrijos).
}

Fim $\mathrm{H}$ from $E$. coli, respectively) have been extensively studied and detailed knowledge of their structure and binding specificities is available. This has greatly facilitated the design of high affinity glycoconjugates that can effectively compete with host cell surface ligands [11].

Candida albicans is a dimorphoric yeast that can interconvert from single cells to hyphal forms, and exists in a commensal state in the mucosae and gastrointestinal tract [12]. In immunocompromised patients $C$. albicans induces a range of superficial and systemic infections [13], and is the third leading cause of infections related to medical devices such as catheters [14]. Adherence of C. albicans to host cells plays an important role in pathogenesis, as it allows the establishment of a strong link to host cell surfaces and provides a focal point for infection by enabling persistence in harsh environments such as the mouth [15]. Interestingly, this highly adherent organism is also the most pathogenic Candida species and the major cause of fungal infections [16], indicating that its highly infectious rate may be related to its strong adherence capacity. In addition, $C$. albicans expresses host regulator binding proteins such as phosphoglycerate mutase (gpm1) [17] and $\mathrm{pH}$-regulated antigen 1 (pra1) [18] that bind to immune regulators such as Factor $\mathrm{H}$ and FHL-1 to avoid immune detection, demonstrating that through adherence, $C$. albicans can block activation of immune system 
regulators [19].

The oral cavity, in particular, provides surfaces to which C. albicans can adhere, such as buccal epithelial cells (BECs). C. albicans is capable of adhering to host cells through the interaction of the yeast cell wall and epithelial cell surfaces [16]. Adherence to abiotic and biotic surfaces is achieved by both nonspecific and specific mechanisms: non-specific interactions involve cell surface hydrophobicity (CSH) [20]. CSH does not play a dominant role in the adherence process but has been known to maintain specific interactions between the yeast and the host [21]. Specific adherence mechanisms occur via the binding of adhesins to receptors on the host cell surface through lectin-like and proteinprotein interactions [22]. Initial reports indicate that some C. albicans adhesins recognise and bind to a broad range of cell surface glycans, which include glycosphingolipids such as lactosylceramide [23] and asialo-GM1, ${ }^{24}$ and host oligosaccharides containing fucose [25] (Fuc) and $N$-acetyl-glucosamine (GlcNAc) [26].

These findings provide evidence that cell surface glycans are important receptors for $C$. albicans and warrant the development of anti-adherence ligands that can mimic them, thus disrupting C. albicans - epithelial cell interactions. These compounds could represent a promising strategy to overcome fungal infections. However, the lack of structural knowledge of the fungal adhesins that recognise these carbohydrates hampers a focused design approach such as those described earlier. In this study, we opted instead to screen a small library of synthetic glycoconjugates with a diverse presentation of binding epitopes in order to identify structural features that can lead to effective inhibition of fungal adherence. Thus, we herein report the synthesis of aromatic-core glycoconjugates (AGC) which display some of the glycan residues reported to mediate $C$. albicans adherence to epithelial cells and their subsequent evaluation as inhibitors of the adherence of C. albicans to BECs.

\section{Results and discussion}

\subsection{Synthesis}

There are numerous examples of glycoconjugates built upon aromatic scaffolds, many of which are intended as ligands for adhesins [27], carbohydrate-binding proteins [28] or sensors for the detection of pathogens $[29,30]$. The popularity of AGCs is partly due to the versatility in functionality and the substitution patterns that can be achieved from readily available starting materials. Thus, we decided to explore 1,3 and 1,3,5 functionalized aromatic derivatives as the starting point in the design of the anti-adherence AGCs library (Scheme 1, Figures SI.1-3).

It is well known that multivalency can be an important factor that modulates carbohydrate-protein interactions [31]. Hence, mono- (compounds 1a-c), di- (compounds 2a-f) and trivalent analogues (compounds 3a-c) were investigated. Carbohydrate moieties present in the epithelial cell surface and reported to bind C. albicans adhesins were selected to be grafted onto the aromatic scaffold: these included galactose, fucose, mannose, glucose, $\mathrm{N}$ acetyl glucosamine and lactose derivatives. Triazolyl-containing spacer groups of different lengths, generated by means of Copper-Catalyzed Azide-Alkyne Cycloaddition (CuAAC) reactions, connected the glycosides to the central aromatic core. This methodology has been found to be extremely useful and reliable for the efficient synthesis of numerous glycoconjugates [32]. With this modular approach, we were able to readily assemble a small collection of glycoconjugates in which (i) the carbohydrate moiety, (ii) the valency and (iii) the distance between the binding epitopes were varied. This provided sufficient structural diversity for an initial screening of the requirements for fungal anti-adherence activity.

The synthesis of one of the divalent analogues, galactoside $\mathbf{2 a}$, depicted in Scheme 2, is representative for the synthesis of the other members of the AGCs library. 5-Aminoisophthalic acid was reacted with propanoyl chloride. The resulting dicarboxilic acid was reacted with propargyl amine using freshly prepared 4-(4,6Dimethoxy-1,3,5-triazin-2-yl)-4-methylmorpholinium chloride (DMTMM) to give diamide $\mathbf{6}$ in $78 \%$ yield [33]. The attachment of the carbohydrate moiety to the aromatic scaffold was effected by means of the CuAAC reaction: in this example, 2,3,4,6-tetra-Oacetyl-1- $\beta$-azido-galactoside [34] was reacted with compound $\mathbf{6}$ using copper sulphate and sodium ascorbate as the catalytic system. If the cycloaddition was carried out using conventional heating, the reaction times were long (up to 4 days) and the yields were moderate. However, we found that if the reaction was carried out using microwave (MW) irradiation, it proceeded with yields up to $82 \%$ for the protected glycoconjugate $7 \mathbf{a}$ and with a drastic reduction in reaction times [35]. The deacetylation of compound 7a was accomplished under mild basic conditions to give the galactosyl AGC 2a in 96\% yield. Following comparable synthetic schemes (see Supporting Information, Schemes SI.1-3), the remaining mono-, diand trivalent AGCs were readily prepared in moderate to good yields.

\subsection{Biological Evaluation}

All of the glycoconjugates (with exception of monovalent fucosyl derivative, compound $\mathbf{1 b}$ ) were found to be soluble in water. The toxicity of the compounds against $C$. albicans was firstly evaluated. None of the compounds showed significant ability to inhibit the growth of the yeast cells at the range of concentrations used in the subsequent adherence assays (see Figure SI.4). This implies that any reduction of adherence observed is not due to toxic effects. The ability of the glycoconjugates to inhibit the adherence of $C$. albicans was then evaluated in different assays:

\subsubsection{Exclusion assay}

The initial adherence assay was performed by treating C. albicans with the glycoconjugates, allowing for an incubation period and then exposing the treated yeast cells to the exfoliated BECs. The percentage increase or decrease of the number of C. albicans cells adhering to BECs compared to the adherence of the untreated yeast is represented in Table 1 .

These results show the impact of the valency effect in the antiadherence ability of the AGCs: monovalent compounds, in which only one carbohydrate moiety is present, are considerably less active than their di- and trivalent counterparts. In addition, it can be clearly seen that the galactosyl derivatives ( $\mathbf{2 a}, \mathbf{2 c}, \mathbf{3 a}$ and $\mathbf{3 c}$ ) and the $N$-acetyl glucosamine derivative $\mathbf{2 e}$ are much more efficient at preventing the yeast adherence than any of the other glycoconjugates: in particular, divalent galacoside $\mathbf{2 a}$ was identified as the most active compound of the AGCs library screened, showing a remarkable $80 \%$ decrease in adherence of the yeast to the BECs after treatment. Interestingly, compound $\mathbf{4}$, a structural analogue of $\mathbf{2 a}$ in which one of the galactosyl moieties has been replaced by mannose, is only capable of producing a $24 \%$ reduction in yeast adherence. This highlights the importance of a divalent galactosyl pattern as a recognition motif. The linker connecting the galactosyl moieties to the aromatic scaffold appears to also influence the antiadherence ability of the glycoconjugates: the more flexible $\mathrm{O}$-galactosides 1c, 2c, 3c inhibited yeast adherence less effectively than their respective analogues $\mathbf{1 a}, \mathbf{2 a}, \mathbf{3 a}$, in which the triazolyl spacer group is directly attached to the anomeric galactosyl carbon. In addition, divalent galactoside $\mathbf{5}$, which features no linkers, was only 

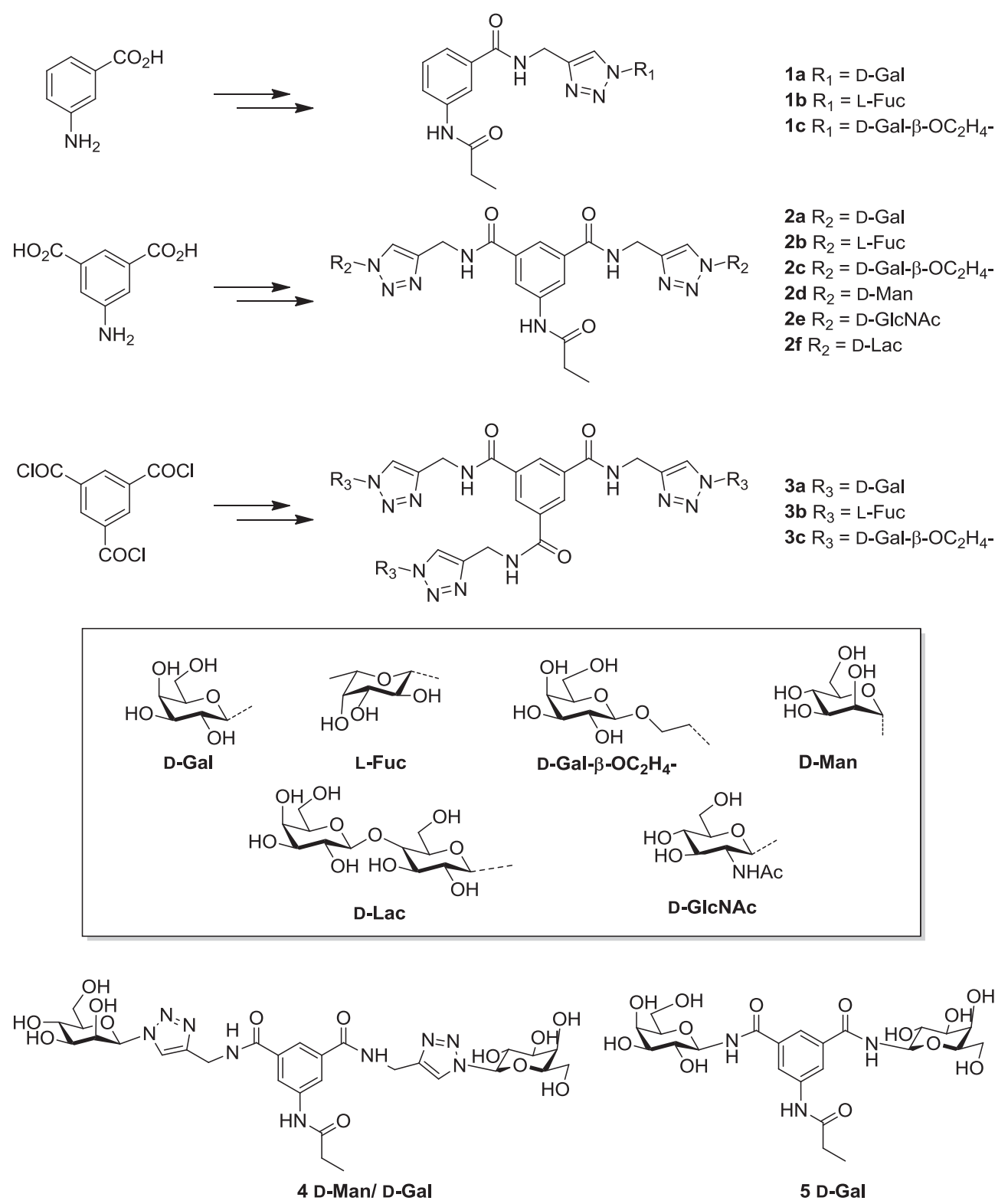

Scheme 1. Chemical structures and starting materials used in the synthesis of the anti-adherence AGCs library.

able to induce a $26 \%$ reduction in adherence of $C$. albicans to BECs. The divalent galactoside $\mathbf{2 a}$ was then evaluated at lower concentrations (Fig. 1a). Significantly, the anti-adherence ability of this compound was maintained at a 100 -fold dilution concentration $(0.1 \mathrm{mg} / \mathrm{mL}, 138 \mu \mathrm{M}))$.

\subsubsection{Competitive assay}

The best performing compound (divalent galactosides 2a) was then evaluated in a competition assay, in which its anti-adherence ability was tested in the presence of both C. albicans and BECs. Coincubation with compounds 2a resulted in a reduction in adherence of yeast cells to BECs of $65 \%$, even at the lowest concentration (Fig. 1b).

\subsubsection{Displacement assay}

A further assay was performed where glycoconjugate 2a $(0.1 \mathrm{mg} / \mathrm{mL}, 138 \mu \mathrm{M}))$ was added to a mixture of $C$. albicans and $\mathrm{BEC}$, which had been previously incubated together. The ability of the compound to reverse the adherence of the yeast to the BECs was then examined. Two controls were used in this assay: control 1 involved the assessment of the binding of $C$. albicans to BECs prior to compound exposure; control 2 involved BECs and adherent yeast cells being re-incubated in PBS for 90 min prior to a second filtration step. It was found that $\mathbf{2 a}$ imparted a reduction in adherence of $56 \%$ (compared to the control 1) and 31\% (compared to the control 2) (Fig. 1). These results suggest that divalent galactoside $\mathbf{2 a}$ bind effectively to $C$. albicans preventing its interaction with BECs (Fig. 1d).

\subsection{Fluorescence imaging}

A fluorescently labelled analogue of galactosylated AGC 2a, compound $\mathbf{8}$ (Fig. 2), was synthesized to investigate possible sites of interaction of anti-adherence AGCs with C. albicans (Scheme SI-6). As controls, $C$. albicans cells with no treatment were imaged under an Olympus Fluoview 1000 confocal microscope to discard yeast 


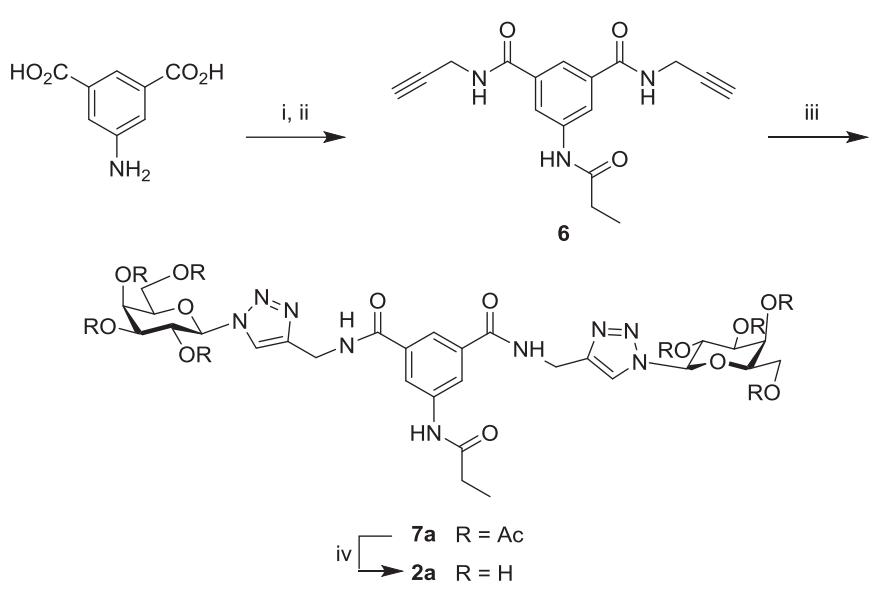

Scheme 2. Synthesis of galactosyl AGC 2a. Reagents and conditions: i) $\mathrm{C}_{2} \mathrm{H}_{5} \mathrm{COCl}, \mathrm{NEt}_{3}$, THF, $\mathrm{N}_{2}, \mathrm{rt}, 22 \mathrm{~h}, 77 \%$; ii) DMTMM, propargyl amine, DMF, $\mathrm{N}_{2}, 16 \mathrm{~h}, 78 \%$; iii) 2,3,4,6tetra- $O$-acetyl-1- $\beta$-azido-galactoside, $\mathrm{CuSO}_{4} \cdot 5 \mathrm{H}_{2} \mathrm{O} / \mathrm{Na} \mathrm{Asc}, \mathrm{CH}_{3} \mathrm{COCH}_{3} / \mathrm{H}_{2} \mathrm{O}, 100{ }^{\circ} \mathrm{C}$ in $\mathrm{MW}, 10 \mathrm{~min}, 84 \%$; iv) methanol, $\mathrm{NEt}_{3}, \mathrm{H}_{2} \mathrm{O}, 45^{\circ} \mathrm{C}, 6 \mathrm{~h}, 94 \%$.

Table 1

Effect of AGCs on adherence of $C$. albicans to BECs (estimated according to exclusion assays, at AGCs concentration $=10 \mathrm{mg} / \mathrm{mL}$. SE in all cases was less than $10 \%$ of mean change in adherence).

\begin{tabular}{ll}
\hline AGCs & \% Increase/Decrease of Adherence \\
\hline 1a D- Gal & -14.5 \\
1b L- Fuc & -2 \\
1c D- Gal- $\beta-\mathrm{OC}_{2} \mathrm{H}_{4}$ & -7.5 \\
2a D-Gal & -80 \\
2b L-Fuc & -8 \\
2c D-Gal- $\beta-\mathrm{OC}_{2} \mathrm{H}_{4}$ & -35 \\
2d D-Man & +3 \\
2e D-GlcNAc & -45 \\
2f D-Lac & +6.5 \\
3a D-Gal & -45 \\
3b L-Fuc & -30 \\
3c D-Gal- $\beta-\mathrm{OC}_{2} \mathrm{H}_{4}$ & -42 \\
4 D-Gal/D-Man & -24 \\
5 D-Gal & -26 \\
\hline
\end{tabular}

autofluorescence (Fig. 2a). In addition, C. albicans cells were incubated with fluorescein isothiocyanate (FITC, Fig. 2b). Fluorescein derivative galactoside $\mathbf{8}$ was then co-incubated with $C$. albicans cells and the cells were imaged (Fig. 2c). In this case, strong localized fluorescence can be clearly observed. From these images, it can be deduced that compound $\mathbf{8}$ is interacting with the surface of the yeast cells.

These results indicate that the valency of the AGCs strongly influences their anti-adherence ability: the monovalent derivatives 1a-c did not show any significant activity while the trivalent derivatives 3a-c were moderate inhibitors, with the galactosyl derivatives $3 \mathbf{a}$ and $3 \mathbf{c}$ achieving as high as $45 \%$ and $42 \%$ reduction of adherence of $C$. albicans to BECs, respectively. Nevertheless, this study was focused in the divalent AGCs based on a 5aminoisophthalic acid scaffold, which may allow for further synthetic versatility.

The results from the anti-adherence assays highlight the potential of divalent galactosyl AGC $2 a$ as an inhibitor of the adherence of $C$. albicans to BECs. This compound consistently showed the best anti-adherence activity in the three types of assays performed (with up to $80 \%$ reduction of adherence in the exclusion assays). Interestingly, divalent compounds analogue in structure to $2 \mathrm{a}$ but featuring carbohydrate moieties other than galactose (compounds 2b, 2d-f) were not as efficient adherence inhibitors as 2a: the second best performing AGC was the $N$-acetyl glucosamine derivative $\mathbf{2 f}$ ( $45 \%$ reduction of adherence in the exclusion assays). These results suggest that the divalent presentation of the galactose epitopes achieved in compound 2a is important in mediating adherence to $C$. albicans. Polysaccharides and adhesins present in C. albicans cell wall mediate many of the adhesion processes of the yeast [36]. Initial research indicated that the addition of galactose or galactosamine reduced $C$. albicans attachment to buccal mucosal cells in vitro [37]. However, this is in contrast to a study in which the pre-treatment of $C$. albicans with galactose failed to inhibit adherence [38]. It has also been reported that $C$. albicans binds specifically to cell surface glycosphingolipids with terminal galactosyl residues such as lactosylceramide [Gal- $\beta-(1-4)-G l c-\beta-(1-1)$ Cer] [23] and asialo-GM $_{1} \quad[$ Gal- $\beta-(1-3)-G a l N A c-\beta-(1-4)-G a l-\beta-(1-4)-G l c-\beta-(1-$ $1)$ Cer] by means of fimbrial proteins [24]. This study also reports that the synthetic disaccharide derivative GalNAc- $\beta-(1-4)-G a l-\beta$ $\mathrm{O}\left(\mathrm{CH}_{2}\right)_{8} \mathrm{CO}_{2} \mathrm{CH}_{3}$ was able to inhibit the binding of $C$. albicans fimbriae to BECs in vitro. More recently, a synthetic disaccharide (Fimbrigal-P) also featuring the terminal GalNAc- $\beta-(1-4)-G a l$ motif, was found to reduce fungal burden in an in vivo model of oral candidiasis [39]. However, to the best of our knowledge, there are no Structure-Activity Relationship (SAR) studies of synthetic glycoconjugates regarding inhibition of $C$. albicans adherence that have identified terminal galactosides as key epitopes mediating yeast adhesion. A recent study has linked the binding specificities of some $C$. albicans adhesins (from the Als family) to human cell surface glycans based on glycan array screening results: a predicted glycan determinant for some of these proteins was a di-LacNAc (Gal- $\beta-1,4-G l c N A c)$ disaccharide [40]. Further studies are currently going on in our laboratory to identify the fungal adhesin that lead compound $\mathbf{2 a}$ may be binding to.

\section{Conclusion}

In conclusion, this work reports the synthesis of a small library of AGCs designed to conduct a preliminary SAR study on their ability to inhibit the adherence of the pathogenic yeast $C$. albicans to BECs. The anti-adherence assays allowed for the identification of divalent galactosyl derivative $\mathbf{2 a}$ as an efficient inhibitor of C. albicans adherence, with 2 a being able to displace over $50 \%$ of yeast cells already attached to BECs. The precise three-dimensional presentation of the galactosyl moieties in 2a appears to be a requirement for efficient adherence inhibition, which suggest that AGC 2a is interfering with a specific recognition process part of the complex $C$. albicans adherence mechanisms. Fluorescence studies suggest that a potential target for $\mathbf{2 a}$ could be indeed a fungal cell wall adhesin. The synthetic accessibility and high efficacy shown by 2a in the biological assays make this compound a promising lead for development of new fungal anti-adherence agents, less prone to the appearance of resistance mechanisms than conventional fungicidal treatments.

\section{Experimental section}

Chemistry. General Methods: All reagents for synthesis were bought commercially and used without further purification. Tetrahydrofuran (THF) was freshly distilled over sodium wire and benzophenone. Dichloromethane (DCM) was freshly distilled over $\mathrm{CaH}_{2}$ prior to use. Reactions were monitored with thin layer chromatography (TLC) on Merck Silica Gel $F_{254}$ plates. Detection was effected by UV $(\lambda=254 \mathrm{~nm})$ or charring in a mixture of $5 \%$ sulfuric acid-ethanol. NMR spectra were recorded using Bruker Ascend 500 spectrometer at 293K. All chemical shifts were referenced relative to the relevant deuterated solvent residual peaks. Assignments of the NMR spectra were deduced using ${ }^{1} \mathrm{H}$ NMR and ${ }^{13} \mathrm{C}$ NMR, along with 2D experiments (COSY, HSQC and HMBC). 

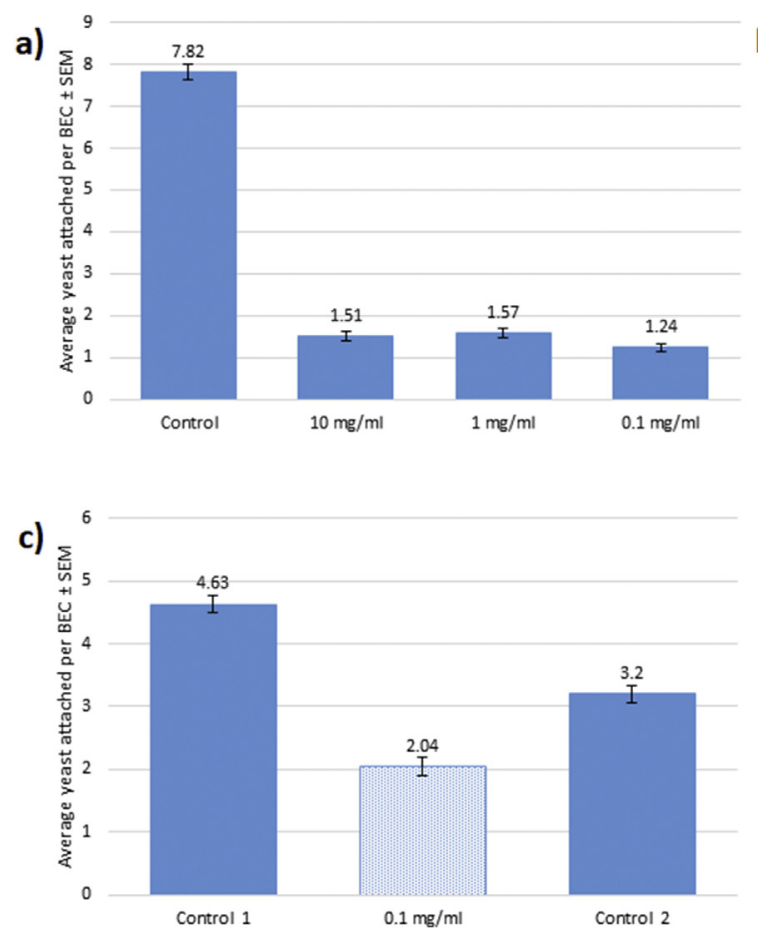

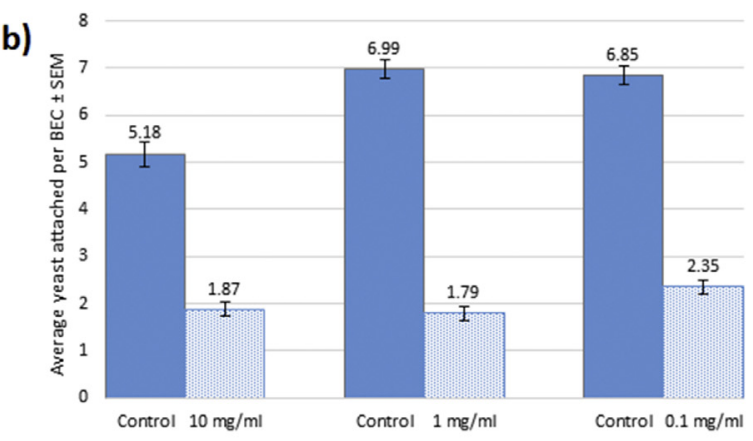

d)
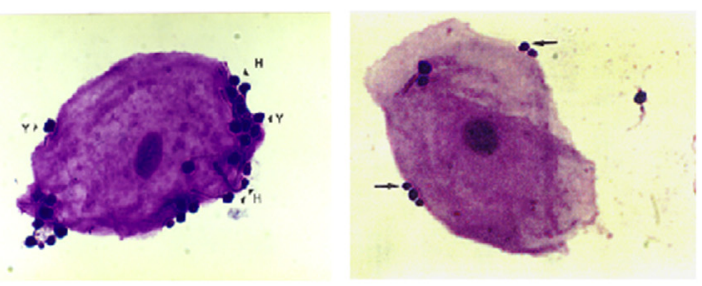

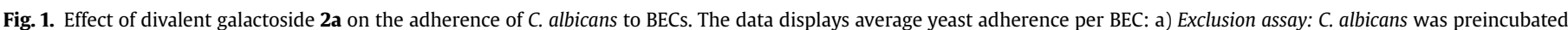

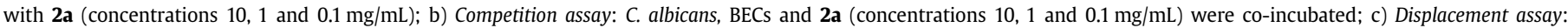

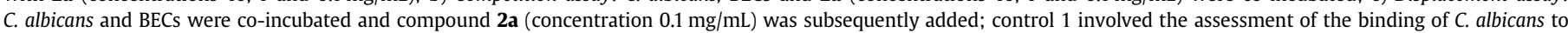

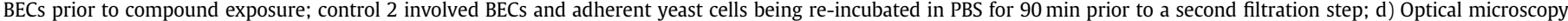
image of $C$. albicans attached to BEC before (right) after (left) treatment with 2a.
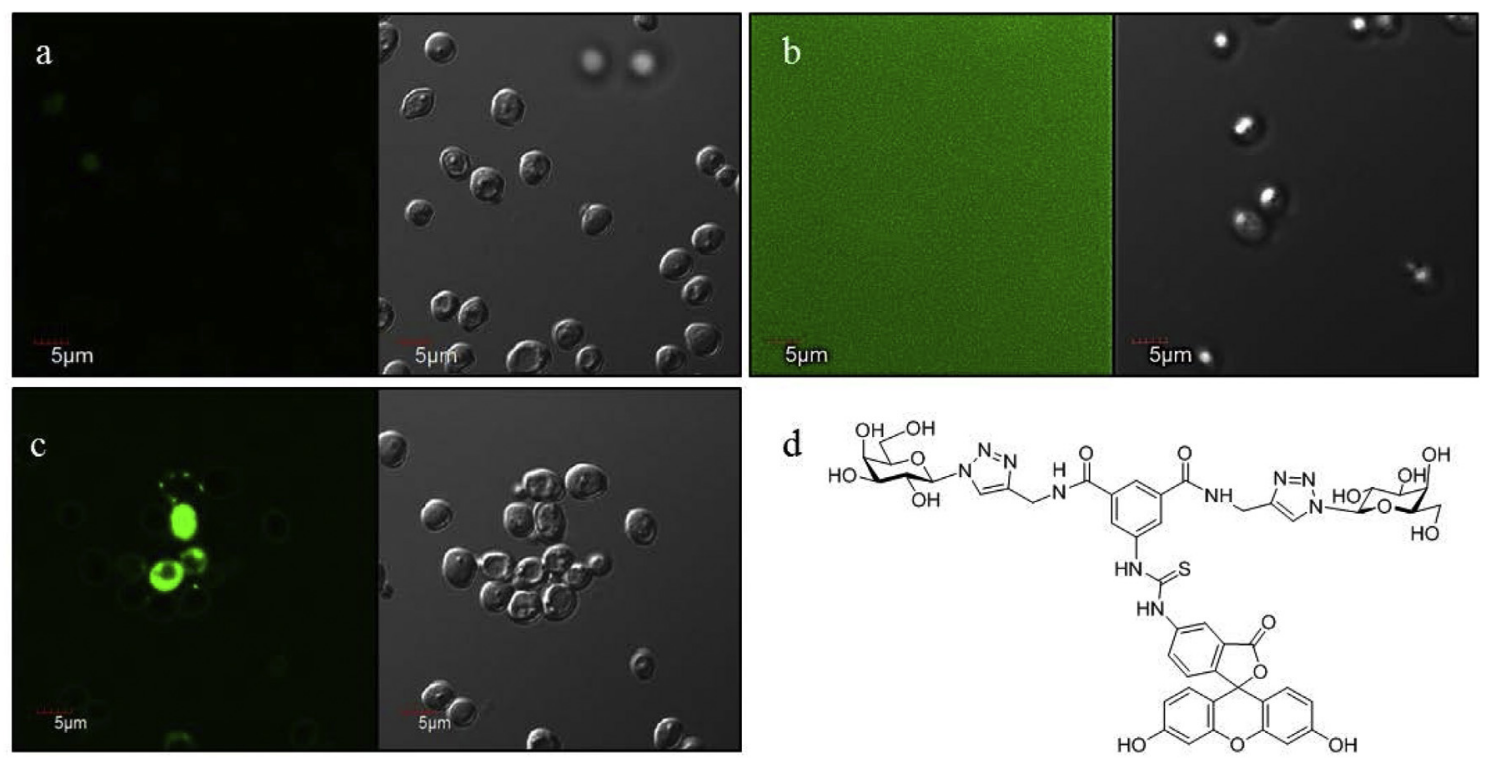

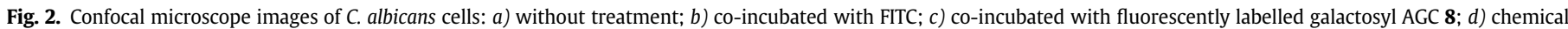
structure of galactoside 8 . A wavelength of $488 \mathrm{~nm}$ laser was used for excitation and emission was detected at 500-600 $\mathrm{nm}$.

Chemical shifts are reported in ppm. Flash chromatography was performed with Merck Silica Gel 60. Microwave reactions were carried out using a CEM Discover Microwave Synthesizer. Optical rotations were obtained from an AA-100 polarimeter and $[\alpha]_{D}$ values are given in $10^{-1} \mathrm{~cm}$ [2] $\cdot \mathrm{g}^{-1}$. High performance liquid chromatography analysis (HPLC, Waters Alliance 2695) was performed in final compounds and indicated purity of $95 \%$ based on integrations without the use of an internal standard. High resolution mass spectrometry (HRMS) was performed on an Agilent-LC 1200 Series coupled to a 6210 Agilent Time-Of-Flight (TOF) mass spectrometer equipped with an electrospray source in both positive and negative (ESI+/-) modes. Infrared spectra were obtained as a film on $\mathrm{NaCl}$ plates or as $\mathrm{KBr}$ disks in the region 4000-400 $\mathrm{cm}^{-1}$ on a Perkin Elmer Spectrum 100 FT-IR spectrophotometer. Synthetic schemes and spectroscopic data for all members of the ACG library are provided in the SI. 
4.1. General Copper-Catalyzed Azide-Alkyne Cycloaddition (CuAAC) reaction procedures

\subsubsection{Method A}

Copper sulphate pentahydrate $(20 \mathrm{mg})$ and sodium ascorbate (40 mg) were added to a solution of the acetylated sugar azide (1,25 equiv per propargyl group) and the corresponding propargyl amide scaffold in acetone/water (2:1 ratio). The reaction was allowed to stir at rt until deemed complete by TLC analysis (typically 16-24 h). The solvent was removed in vacuo. The residue was dissolved in DCM, washed with water $(\mathrm{x} 3)$ and dried $\left(\mathrm{MgSO}_{4}\right)$. The mixture was filtered and the solvent was removed in vacuo to yield the crude product, which was purified by silica gel column chromatography (DCM:MeOH 98:2-93:7) to give the corresponding product.

\subsubsection{Method $B$}

Copper sulphate pentahydrate $(20 \mathrm{mg})$ and sodium ascorbate (40 mg) were added to a solution of the acetylated sugar azide (1,25 equiv per propargyl group) and the corresponding propargyl amide scaffold in acetonitrile/water (2:1 ratio). The reaction was allowed to stir in the MW at $100{ }^{\circ} \mathrm{C}$ until deemed complete by TLC analysis (typically 5-15 min). The solvent was removed in vacuo. The residue was dissolved in DCM, washed with water (x3) and dried $\left(\mathrm{MgSO}_{4}\right)$. The mixture was filtered and the solvent was removed in vacuo to yield the crude product, which was purified by silica gel column chromatography (DCM:MeOH 98:2-93:7) to give the corresponding product.

\subsubsection{General acetyl ester hydrolysis procedure}

The acetylated glycoconjugate was dissolved in methanol/water (2:1 ratio). $\mathrm{NEt}_{3}(0.1 \mathrm{~mL})$ was added and the reaction mixture was allowed to stir at $45{ }^{\circ} \mathrm{C}$ until completion (typically $6-18 \mathrm{~h}$ ). The solution was cooled to rt, Amberlite $\mathrm{H}^{+}$was added and the mixture was allowed to stir for $30 \mathrm{~min}$. The solution was filtered and the solvent was removed in the rotatory evaporator and the residue was dried under high vacuum or lyophilized to give the deprotected glycoconjugate.

4.1.3.1. $N, N^{\prime}$-di(prop-2-yn-1-yl)-5-propionamidoisophthalamide (6). 5-aminoisophathalic acid ( $5 \mathrm{~g}, 27.6 \mathrm{mmol})$ was dissolved in anhydrous THF $(60 \mathrm{~mL})$ under $\mathrm{N}_{2}$ and propionyl chloride $(2.7 \mathrm{~mL}$, $30.4 \mathrm{mmol}$ ) was added dropwise. The mixture was allowed to stir for $5 \mathrm{~min}$ and $\mathrm{NEt}_{3}(5 \mathrm{~mL}, 35.8 \mathrm{mmol}$ ) was added slowly. The reaction was left to stir for $22 \mathrm{~h}$. The solvent was removed under reduced pressure, and the residue was dissolved in hot methanol. The insoluble material was filtered off and the filtrate was evaporated in a rotatory evaporator to give 5-propionoamidoisophthalic acid [33], which was used without further purification. (5.03 g, 77\%). 5-propionoamidoisophthalic acid $(0.78 \mathrm{~g}, 3.27 \mathrm{mmol})$ and DMTMM ( $1.99 \mathrm{~g}, 7.20 \mathrm{mmol})$ were suspended in anhydrous DMF $(25 \mathrm{~mL})$ under $\mathrm{N}_{2}$. After $10 \mathrm{~min}$, propargylamine $(0.46 \mathrm{~mL}$, $7.2 \mathrm{mmol}$ ) was added and the reaction mixture went clear. It was left to stir at $\mathrm{rt}$ for $16 \mathrm{~h}$. The reaction mixture was poured into ice/ water $(30 \mathrm{~mL})$ and the precipitated formed was then filtered and dried on the air to give 6 : white amorphous solid $(0.79 \mathrm{~g}, 78 \%) .{ }^{1} \mathrm{H}$ NMR $\left(500 \mathrm{MHz}\right.$, DMSO-d $\left.d_{6}\right): \delta 10.15\left(\mathrm{~s}, 1 \mathrm{H}, \mathrm{NHCOC} \mathrm{H}_{5}\right), 8.94(\mathrm{t}$, $\left.J=5.3 \mathrm{~Hz}, 2 \mathrm{H}, \mathrm{NHCH}_{2} \mathrm{CCH}\right), 8.18(\mathrm{~s}, 2 \mathrm{H}, \mathrm{Ar}-\mathrm{H}), 7.93(\mathrm{~s}, 1 \mathrm{H}, \mathrm{Ar}-\mathrm{H})$, 4.11-4.00 (m, 4H, $\left.\mathrm{NHCH}_{2} \mathrm{CCH}\right), 3.13\left(\mathrm{~s}, 2 \mathrm{H}, \mathrm{NHCH}_{2} \mathrm{CCH}\right), 2.35$ (q, $\left.J=7.5 \mathrm{~Hz}, 2 \mathrm{H}, \mathrm{CH}_{2} \mathrm{CH}_{3}\right), 1.10\left(\mathrm{t}, J=7.5 \mathrm{~Hz}, 3 \mathrm{H}, \mathrm{CH}_{2} \mathrm{CH}_{3}\right) .{ }^{13} \mathrm{C} \mathrm{NMR}$ $\left(125 \mathrm{MHz}, \mathrm{DMSO}-d_{6}\right): \delta 172.8\left(\mathrm{COC}_{2} \mathrm{H}_{5}\right), 166.2\left(\mathrm{CONHCH}_{2} \mathrm{CCH}\right)$, $140.0(\mathrm{Ar}-\mathrm{C}), 135.3(\mathrm{Ar}-\mathrm{C}), 121.4(\mathrm{Ar}-\mathrm{CH}), 120.7(\mathrm{Ar}-\mathrm{CH}), 81.6$ $\left(\mathrm{CH}_{2} \mathrm{CCH}\right), 73.4\left(\mathrm{CH}_{2} \mathrm{CCH}\right), 29.1\left(\mathrm{CH}_{2} \mathrm{CH}_{3}\right), 10.0\left(\mathrm{CH}_{2} \mathrm{CH}_{3}\right)$. IR $(\mathrm{KBr})$ : 3289.16, 3241.00, 3093.06, 2977.14, 2116.87, 1682.50, $1570.58 \mathrm{~cm}^{-1}$. HRMS (ESI+): $m / z$ calcd for $\mathrm{C}_{17} \mathrm{H}_{17} \mathrm{~N}_{3} \mathrm{O}_{3}+\mathrm{H}^{+}[\mathrm{M}+\mathrm{H}]^{+} 312.1343$, found 312.1361 .
4.1.3.1. $N, N^{\prime}$-di-(2,3,4,6-tetra-O-acetyl- $\beta$-D-galactopyranosyl-1,2,3triazol-4-ylmethylamide)- $N^{\prime \prime}$-propyl-5-aminobenzene-1,3dicarboxamide (7a). Prepared from 6 to 2,3,4,6-tetra-O-acetyl-1- $\beta$ azido-D-galactopyranoside [34], according to Method B: pale yellow amorphous solid (608 $\mathrm{mg}, 84 \%) . \quad \mathrm{R}_{f}=0.29$ (DCM: methanol 9:1). $[\alpha]_{\mathrm{D}}^{21}-4.3$ (c 0.7, DCM). ${ }^{1} \mathrm{H} \mathrm{NMR}\left(500 \mathrm{MHz}, \mathrm{CDCl}_{3}\right): \delta 9.09$ (s, $1 \mathrm{H}$, $\mathrm{NHCOC}_{2} \mathrm{H}_{5}$ ), 8.21 (s, 2H, $\mathrm{NHCH}_{2}$-triaz), 7.97-7.95 (overlapping of $2 \mathrm{~s}, 4 \mathrm{H}, \mathrm{Ar}-\mathrm{H}$ and triaz- $\mathrm{H}), 7.78(\mathrm{~s}, 1 \mathrm{H}, \mathrm{Ar}-\mathrm{H}), 5.89(\mathrm{~d}, J=9.2 \mathrm{~Hz}, 2 \mathrm{H}$, $\mathrm{H}-1$ ), 5.54 (t, $J=9.7 \mathrm{~Hz}, 2 \mathrm{H}, \mathrm{H}-2$ ), 5.49 (d, $J=3.2 \mathrm{~Hz}, 2 \mathrm{H}, \mathrm{H}-4), 5.27$ (dd, $J=10.3,3.2 \mathrm{~Hz}, 2 \mathrm{H}, \mathrm{H}-3), 4.59$ (dd, $J=15.5,5.2 \mathrm{~Hz}, 4 \mathrm{H}, \mathrm{CH}_{2^{-}}$ triaz), $4.29(\mathrm{t}, J=6.5 \mathrm{~Hz}, 2 \mathrm{H}, \mathrm{H}-5), 4.16-4.05\left(\mathrm{~m}, 4 \mathrm{H}, \mathrm{H}-6\right.$ and $\left.\mathrm{H}-6^{\circ}\right)$, 2.30 (q, $\left.J=7.5 \mathrm{~Hz}, 2 \mathrm{H}, \mathrm{CH}_{2} \mathrm{CH}_{3}\right), 2.14$ (s, 3H, OAc), 1.93 (s, 6H, OAc x 2), $1.76(\mathrm{~s}, 3 \mathrm{H}, \mathrm{OAc}), 1.06\left(\mathrm{t}, J=7.5 \mathrm{~Hz}, 3 \mathrm{H}, \mathrm{CH}_{2} \mathrm{CH}_{3}\right) .{ }^{13} \mathrm{C} \mathrm{NMR}$ $\left(125 \mathrm{MHz}, \mathrm{CDCl}_{3}\right): \delta 173.4\left(\mathrm{COC}_{2} \mathrm{H}_{5}\right), 170.4$ (CO of OAc), 170.2 (CO of OAc), 169.9 (CO of OAc), 169.3 (CO of OAc), 166.9 ( $\mathrm{CONHCH}_{2}$-triaz), 145.4 (C-triaz), 139.1, 134.7 (each $\mathrm{Ar}-\mathrm{C}$ ), 121.7 (CH-triaz), 121.4, 120.9 (each $\mathrm{Ar}-\mathrm{CH}$ ), 86.0 (C-1), 73.8 (C-5), 70.8 (C-3), 68.1 (C-2), 67.0 (C-4), 61.2 (C-6), 35.3 ( $\mathrm{CH}_{2}$-triaz), $30.2\left(\mathrm{CH}_{2} \mathrm{CH}_{3}\right), 20.6\left(\mathrm{CH}_{3}\right.$ of OAc), $20.6\left(\mathrm{CH}_{3}\right.$ of $\left.\mathrm{OAc}\right), 20.5\left(\mathrm{CH}_{3}\right.$ of $\left.\mathrm{OAc}\right), 20.2\left(\mathrm{CH}_{3}\right.$ of $\left.\mathrm{OAc}\right), 9.4$ $\left(\mathrm{CH}_{2} \mathrm{CH}_{3}\right)$. IR (film on $\left.\mathrm{NaCl}\right): 3290,2979,2940,2120,1753,1655$, 1599, $1536 \mathrm{~cm}^{-1}$. HRMS (ESI + ): $\mathrm{m} / z$ calcd. for $\mathrm{C}_{45} \mathrm{H}_{56} \mathrm{~N}_{9} \mathrm{O}_{21}+\mathrm{H}^{+}$ $[\mathrm{M}+\mathrm{H}]^{+}$1058.3591, found 1058.3602 .

4.1.3.1. $N, N^{\prime}$-di-(2,3,4-tri-O-acetyl- $\beta$-L-fucopyranosyl-1,2,3-triazol-4ylmethylamide)- $N^{\prime \prime}$-propyl-5-aminobenzene-1,3-dicarboxamide (7b). Prepared from 6 to 2,3,4-tri-O-acetyl-1- $\beta$-azido-L-fucopyranoside [41] according to Method B: yellow amorphous solid (93 mg, 62\%). $\mathrm{R}_{f}=0.44$ (DCM:MeOH 9:1). $[\alpha]_{\mathrm{D}}^{19}+1.6$ (c 0.9 , DCM). ${ }^{1} \mathrm{H}$ NMR $\left(500 \mathrm{MHz}, \mathrm{CDCl}_{3}\right): \delta 8.37\left(\mathrm{~s}, 1 \mathrm{H}, \mathrm{NHCOC}_{2} \mathrm{H}_{5}\right), 7.97(\mathrm{~s}, 2 \mathrm{H}$, triaz-H), $7.94(\mathrm{~s}, 2 \mathrm{H}, \mathrm{Ar}-\mathrm{H}), 7.83\left(\mathrm{t}, J=5.1 \mathrm{~Hz}, 2 \mathrm{H}, \mathrm{CONHCH}_{2}\right.$-triaz), $7.70(\mathrm{~s}$, $1 \mathrm{H}, \mathrm{Ar}-\mathrm{H}), 5.84(\mathrm{~d}, J=9.2 \mathrm{~Hz}, 2 \mathrm{H}, \mathrm{H}-1), 5.58-5.51(\mathrm{~m}, 2 \mathrm{H}, \mathrm{H}-2), 5.38$ (d, $J=3.3 \mathrm{~Hz}, 2 \mathrm{H}, \mathrm{H}-4), 5.27-5.23$ (m, 2H, H-3), 4.66 (dd, $J=15.3$, $5.7 \mathrm{~Hz}, 4 \mathrm{H}, \mathrm{CH}_{2}$-triaz), 4.15 (q, $J=6.4 \mathrm{~Hz}, 2 \mathrm{H}, \mathrm{H}-5$ ), 2.38 (qd, $J=7.7$, $3.7 \mathrm{~Hz}, 2 \mathrm{H}, \mathrm{CH}_{2} \mathrm{CH}_{3}$ ), 2.22 (s, 6H, OAc), 1.99 (s, 6H, OAc), 1.83 (s, 6H, $\mathrm{OAc}), 1.24(\mathrm{~d}, J=6.4 \mathrm{~Hz}, 6 \mathrm{H}, \mathrm{H}-6), 1.17\left(\mathrm{t}, J=7.5 \mathrm{~Hz}, 3 \mathrm{H}, \mathrm{CH}_{2} \mathrm{CH}_{3}\right) .{ }^{13} \mathrm{C}$ NMR ( $\left.125 \mathrm{MHz}, \mathrm{CDCl}_{3}\right): \delta 172.8\left(\mathrm{NHCOC}_{2} \mathrm{H}_{5}\right), 170.5$ (CO of OAc), 169.9 (CO of OAc), 169.4 (CO of OAc), 166.7 ( $\mathrm{CONHCH}_{2}$-triaz), 145.5 (C-triaz), 139.1 (Ar-C), 135.0 (Ar-C), 121.4 (CH-triaz), 121.2 $(\mathrm{Ar}-\mathrm{CH}), 120.5(\mathrm{Ar}-\mathrm{CH}), 86.3(\mathrm{C}-1), 72.8(\mathrm{C}-5), 71.3(\mathrm{C}-3), 69.9(\mathrm{C}-$ 4), 68.2 (C-2), $35.5\left(\mathrm{CH}_{2}\right.$-triaz), $30.4\left(\mathrm{CH}_{2} \mathrm{CH}_{3}\right), 20.7\left(\mathrm{CH}_{3}\right.$ of $\left.\mathrm{OAc}\right)$, $20.5\left(\mathrm{CH}_{3}\right.$ of $\left.\mathrm{OAc}\right), 20.3\left(\mathrm{CH}_{3}\right.$ of OAc), 16.1 (C-6), $9.5\left(\mathrm{CH}_{2} \mathrm{CH}_{3}\right)$. IR (film on $\mathrm{NaCl}$ ): $3318,2924,1749,1656,1535 \mathrm{~cm}^{-1}$. HRMS (ESI+): $m / z$ calcd for $\mathrm{C}_{41} \mathrm{H}_{51} \mathrm{~N}_{9} \mathrm{O}_{17}+\mathrm{H}^{+}[\mathrm{M}+\mathrm{H}]^{+}$942.9130, found 942.9142 .

4.1.3.1. $N, N^{\prime}$-di-[2-O-(2,3,4,6-tetra-O-acetyl- $\beta$-D-galactopyranosyl)ethyl-1,2,3-triazol-4-ylmethylamide)- $N^{\prime \prime}$-propyl-5-aminobenzene1,3-dicarboxamide (7c). Prepared from 6 and 2-O-(2,3,4,6-tetra-Oacetyl- $\beta$-D-galactopyranosyl)ethyl azide [42] according to Method B: yellow amorphous solid (545 mg, 82\%). $\mathrm{R}_{f}=0.38$ (DCM:MeOH 9:1). $[\alpha]_{\mathrm{D}}^{25}-9.1$ (c 1.1, DCM). ${ }^{1} \mathrm{H}$ NMR (500 MHz, $\left.\mathrm{CDCl}_{3}\right): \delta 9.11(\mathrm{~s}, 1 \mathrm{H}$, $\left.\mathrm{NHCOC}_{2} \mathrm{H}_{5}\right), 8.14$ (s, 2H, CONHCH 2 -triaz), 7.96 (s, 2H, Ar-H), 7.64 (d, $J=16.6 \mathrm{~Hz}, 3 \mathrm{H}, \mathrm{Ar}-\mathrm{H}$ and triaz-H), $5.30(\mathrm{~d}, J=3.2 \mathrm{~Hz}, 2 \mathrm{H}, \mathrm{H}-4), 5.07$ (dd, $J=10.3,8.1 \mathrm{~Hz}, 2 \mathrm{H}, \mathrm{H}-2$ ), 4.94 (dd, $J=10.5,3.2 \mathrm{~Hz}, 2 \mathrm{H}, \mathrm{H}-3$ ), 4.66-4.36 (m, $10 \mathrm{H}, \mathrm{CH}_{2}$-triaz and $\mathrm{CH}_{2} \mathrm{CH}_{2} \mathrm{O}$ and $\mathrm{H}-1$ ), 4.15 (dd, $J=13.6,6.4 \mathrm{~Hz}, 2 \mathrm{H}, \mathrm{CHO}-\mathrm{Gal}$ ), 4.09-4.01 (m, 4H, H-6 and H-6'), 3.88 (ap t, $J=6.4 \mathrm{~Hz}, 4 \mathrm{H}, \mathrm{CHO}-\mathrm{Gal}$ and $\mathrm{H}-5), 2.27$ (d, $J=7.0 \mathrm{~Hz}, 2 \mathrm{H}$, $\mathrm{CH}_{2} \mathrm{CH}_{3}$ ), 2.06 (s, 6H, OAc), 1.95 (s, 6H, OAc), 1.89 (d, $J=2.1 \mathrm{~Hz}, 12 \mathrm{H}$, OAc x2), $1.03\left(\mathrm{t}, J=7.3 \mathrm{~Hz}, 3 \mathrm{H}, \mathrm{CH}_{2} \mathrm{CH}_{3}\right) .{ }^{13} \mathrm{C} \mathrm{NMR}\left(125 \mathrm{MHz}, \mathrm{CDCl}_{3}\right)$ : $\delta 173.2\left(\mathrm{NHCOC}_{2} \mathrm{H}_{5}\right), 170.4$ (CO of OAc), 170.2 (CO of OAc), $170.0(\mathrm{CO}$ of OAc), 169.7 (CO of OAc), 166.8 ( $\mathrm{CONHCH}_{2}$-triaz), 144.7 (C-triaz), $139.3(\mathrm{Ar}-\mathrm{C}), 134.7(\mathrm{Ar}-\mathrm{C}), 123.6(\mathrm{CH}-\mathrm{triaz}), 121.1(\mathrm{Ar}-\mathrm{CH}), 120.2$ $(\mathrm{Ar}-\mathrm{CH}), 100.8(\mathrm{C}-1), 70.7$ (C-5), $70.6(\mathrm{C}-3), 68.5(\mathrm{C}-2), 67.5$ $\left(\mathrm{CH}_{2} \mathrm{CH}_{2} \mathrm{O}\right), 66.9(\mathrm{C}-4), 61.1(\mathrm{C}-6), 50.00\left(\mathrm{CH}_{2} \mathrm{CH}_{2} \mathrm{O}\right), 35.5\left(\mathrm{CH}_{2}-\right.$ triaz), $30.2\left(\mathrm{CH}_{2} \mathrm{CH}_{3}\right), 20.7\left(\mathrm{CH}_{3}\right.$ of $\left.\mathrm{OAc}\right), 20.6\left(\mathrm{CH}_{3}\right.$ of OAc $), 20.6\left(\mathrm{CH}_{3}\right.$ of $\mathrm{OAc}), 20.5\left(\mathrm{CH}_{3}\right.$ of $\left.\mathrm{OAc}\right), 9.5\left(\mathrm{CH}_{2} \mathrm{CH}_{3}\right)$. IR (film on $\left.\mathrm{NaCl}\right)$ : 3311, 
3148, 3071, 2980, 1750, 1656, 1599, $1543 \mathrm{~cm}^{-1}$. HRMS (ESI+): $\mathrm{m} / \mathrm{z}$ calcd for $\mathrm{C}_{49} \mathrm{H}_{64} \mathrm{~N}_{9} \mathrm{O}_{23}+\mathrm{H}^{+}[\mathrm{M}+\mathrm{H}]^{+} 1146.4115$, found 1146.4208 .

4.1.3.1. $N, N^{\prime}$-di-(2,3,4,6-tetra-O-acetyl- $\alpha$-D-mannopyranosyl-1,2,3triazol-4-ylmethylamide)- $N^{\prime \prime}$-propyl-5-aminobenzene-1,3dicarboxamide (7d). Prepared from 6 to 2,3,4,6-tetra-O-acetyl-1- $\alpha$ azido-D-mannopyranoside [43] according to Method B: sticky, yellow amorphous solid (110 mg, 82\%). $\mathrm{R}_{f}=0.42$ (DCM:MeOH 9:1). $[\alpha]_{\mathrm{D}}^{22}+3$ (c 1, DCM). ${ }^{1} \mathrm{H}$ NMR $\left(500 \mathrm{MHz}, \mathrm{CDCl}_{3}\right): \delta 8.93(\mathrm{~s}, 1 \mathrm{H}$, $\mathrm{NHCOC}_{2} \mathrm{H}_{5}$ ), 8.23 (s, $2 \mathrm{H}, \mathrm{NHCH}_{2}$-triaz), $7.94(\mathrm{~s}, 2 \mathrm{H}$, triaz-H), 7.78 (s, $2 \mathrm{H}, \mathrm{Ar}-\mathrm{H}), 7.55(\mathrm{~s}, 1 \mathrm{H}, \mathrm{Ar}-\mathrm{H}), 6.11(\mathrm{~s}, 2 \mathrm{H}, \mathrm{H}-1), 5.99(\mathrm{~s}, 2 \mathrm{H}, \mathrm{H}-2)$, $5.90(\mathrm{~d}, J=9.8 \mathrm{~Hz}, 2 \mathrm{H}, \mathrm{H}-3), 5.41(\mathrm{t}, J=9.6 \mathrm{~Hz}, 2 \mathrm{H}, \mathrm{H}-4), 4.65-4.54$ (m, $4 \mathrm{H}, \mathrm{CH}_{2}$-triaz), 4.27 (dd, $J=12.5,2.9 \mathrm{~Hz}, 2 \mathrm{H}, \mathrm{H}-6$ ), 4.05 (dd, $J=12.4,3 \mathrm{~Hz}, 2 \mathrm{H}, \mathrm{H}-6$ ) $), 3.97$ (dd, $J=6.0,3.5 \mathrm{~Hz}, 2 \mathrm{H}, \mathrm{H}-5), 2.48-2.33$ $\left(\mathrm{m}, 4 \mathrm{H}, \mathrm{CH}_{2} \mathrm{CH}_{3}\right), 2.17$ (d, $\left.J=1.2 \mathrm{~Hz}, 6 \mathrm{H}, \mathrm{OAc}\right), 2.06(\mathrm{~d}, J=1.6 \mathrm{~Hz}, 6 \mathrm{H}$, OAc), 2.02-1.96 (m, 12H, OAc x2), 1.14 (dd, $J=9.4,5.5 \mathrm{~Hz}, 6 \mathrm{H}$, $\left.\mathrm{CH}_{2} \mathrm{CH}_{3}\right) .{ }^{13} \mathrm{C} \mathrm{NMR}\left(125 \mathrm{MHz}, \mathrm{CDCl}_{3}\right): \delta 173.5\left(\mathrm{COC}_{2} \mathrm{H}_{5}\right), 170.7$ ( $\mathrm{CO}$ of OAc), 170.0 (CO of OAc), 169.9 (CO of OAc), 169.7 (CO of OAc), 166.6 ( $\mathrm{CONHCH}_{2}$-triaz), 145.6 (C-triaz), 138.9 ( $\left.\mathrm{Ar}-\mathrm{C}\right), 134.4$ ( $\left.\mathrm{Ar}-\mathrm{C}\right), 123.5$ (CH-triaz), $121.4(\mathrm{Ar}-\mathrm{CH}), 120.2(\mathrm{Ar}-\mathrm{CH}), 84.2(\mathrm{C}-1), 71.8(\mathrm{C}-5), 69.3$ (C-3), 68.3 (C-2), 65.6 (C-4), 61.7 (C-6), $35.1\left(\mathrm{CH}_{2}\right.$-triaz), 30.3 $\left(\mathrm{CH}_{2} \mathrm{CH}_{3}\right), 20.8\left(\mathrm{CH}_{3}\right.$ of $\left.\mathrm{OAc}\right), 20.7\left(\mathrm{CH}_{3}\right.$ of $\left.\mathrm{OAc}\right), 20.7\left(\mathrm{CH}_{3}\right.$ of $\left.\mathrm{OAc}\right)$, $20.6\left(\mathrm{CH}_{3}\right.$ of $\left.\mathrm{OAc}\right), 20.4\left(\mathrm{CH}_{3}\right.$ of OAc), $9.5\left(\mathrm{CH}_{2} \mathrm{CH}_{3}\right)$. IR (film on $\left.\mathrm{NaCl}\right)$ : $3429,2115,1748,1646 \mathrm{~cm}^{-1}$. HRMS (ESI+): $\mathrm{m} / \mathrm{z}$ calcd for $\mathrm{C}_{45} \mathrm{H}_{56} \mathrm{~N}_{9} \mathrm{O}_{21}+\mathrm{H}^{+}[\mathrm{M}+\mathrm{H}]^{+}$1058.3591, found 1058.3593.

4.1.3.1. $N, N^{\prime}$-di-(2-Acetamido-2-deoxy-3,4,6-tri-O-acetyl- $\beta$-D-glucopyranosyl-1,2,3-triazol-4-ylmethylamide)-1,2,3-triazol-4ylmethylamide)- $N^{\prime \prime}$-propyl-5-aminobenzene-1,3-dicarboxamide (7e). Prepared from 6 and 2-acetamido-2-deoxy-,3,4,6-tri-O-acetyl-1- $\beta$ azido-D-glucopyranoside [44] according to Method B: yellow amorphous solid (60 mg, 42\%). $\mathrm{R}_{f}=0.36$ (DCM:MeOH 9:1). $[\alpha]_{\mathrm{D}}^{26}-30$ (c 0.4, DCM). ${ }^{1} \mathrm{H}$ NMR $\left(500 \mathrm{MHz}, d_{5}\right.$-Pyr): $\delta 10.87(\mathrm{~s}, 1 \mathrm{H}, \mathrm{NH}), 9.88(\mathrm{t}$, $J=5.6 \mathrm{~Hz}, 2 \mathrm{H}, \mathrm{NH}), 9.74(\mathrm{~d}, J=9.0 \mathrm{~Hz}, 2 \mathrm{H}, \mathrm{NH}), 8.90(\mathrm{~s}, 2 \mathrm{H}$, triaz-H), $8.62(\mathrm{~s}, 2 \mathrm{H}, \mathrm{Ar}-\mathrm{H}), 8.57(\mathrm{~s}, 1 \mathrm{H}, \mathrm{Ar}-\mathrm{H}), 6.77(\mathrm{~d}, J=9.9 \mathrm{~Hz}, 2 \mathrm{H}, \mathrm{H}-1)$, $6.06(\mathrm{t}, J=9.6 \mathrm{~Hz}, 2 \mathrm{H}, \mathrm{H}-3$ or 4$), 5.61(\mathrm{t}, J=9.7 \mathrm{~Hz}, 2 \mathrm{H}, \mathrm{H}-2)$, $5.23-5.14(\mathrm{~m}, 2 \mathrm{H}, \mathrm{H}-3$ or 4$), 4.48(\mathrm{dd}, J=12.3,5.0 \mathrm{~Hz}, 2 \mathrm{H}, \mathrm{H}-6), 4.38$ (d, $J=8.2 \mathrm{~Hz}, 2 \mathrm{H}, \mathrm{H}-5), 4.32$ (d, $\left.J=12.3 \mathrm{~Hz}, 2 \mathrm{H}, \mathrm{H}-6{ }^{\circ}\right), 2.43$ (q, $J=7.5 \mathrm{~Hz}, 2 \mathrm{H}, \mathrm{CH}_{2} \mathrm{CH}_{3}$ ), 2.10 (s, 3H, OAc), 2.01 (s, 3H, OAc), 1.89 (s, $3 \mathrm{H}, \mathrm{OAc}), 1.72(\mathrm{~s}, 3 \mathrm{H}, \mathrm{OAc}), 1.19\left(\mathrm{t}, J=7.6 \mathrm{~Hz}, 3 \mathrm{H}, \mathrm{CH}_{2} \mathrm{CH}_{3}\right.$ ). IR (ATR): $3305,3078,2924,2850,1743,1667,1651,1529 \mathrm{~cm}^{-1}$. HRMS (ESI+): $m / z$ calcd for $\mathrm{C}_{45} \mathrm{H}_{57} \mathrm{~N}_{11} \mathrm{O}_{19}+\mathrm{H}^{+}[\mathrm{M}+\mathrm{H}]+1056.3910$, found 1056.3942 .

4.1.3.1. $N, N^{\prime}$-di-[ $\{4-O-(2,3,4,6$-tetra-O-acetyl- $\beta$-D-galactopyranosyl)2,3,6-tri-O-acetyl- $\beta$-D-glucopyranosyl\}-1,2,3-triazol-4$y$ lmethylamide)- $N^{\prime \prime}$-propyl-5-aminobenzene-1,3-dicarboxamide (7f). Prepared from 6 and 4-O-(2,3,4,6-tetra-O-acetyl- $\beta$-D-galactopyranosyl)-2,3,6-tri-O-acetyl-1- $\beta$-azido-D-glucopyranoside [45] according to Method B: sticky, yellow amorphous solid (102 mg, 72\%).

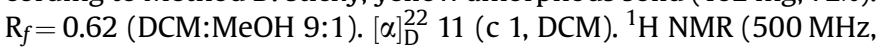
$\left.\mathrm{CDCl}_{3}\right): \delta 8.55\left(\mathrm{~s}, 1 \mathrm{H}, \mathrm{NHCOC} \mathrm{H}_{5}\right), 7.93-7.84\left(\mathrm{~m}, 6 \mathrm{H}, \mathrm{NHCH}_{2}\right.$-triaz, triaz-H and $\mathrm{Ar}-\mathrm{H}), 7.68(\mathrm{~s}, 1 \mathrm{H}, \mathrm{Ar}-\mathrm{H}), 5.84(\mathrm{~d}, J=9.2 \mathrm{~Hz}, 2 \mathrm{H}, \mathrm{H}-1$ Gal), 5.53-5.45 (m, 2H, H-2 Gal), 5.40 (dd, $J=11.2,7.2 \mathrm{~Hz}, 2 \mathrm{H}, \mathrm{H}-3$ Gal), 5.35 (dd, $J=7.0,3.5 \mathrm{~Hz}, 2 \mathrm{H}, \mathrm{H}-4 \mathrm{Glc}$ ), 5.11 (dd, $J=10.3,7.9 \mathrm{~Hz}$, 2H, H-2 Glc), 5.02-4.96 (m, 2H, H-3 Glc), 4.63 (dd, $J=6.8,4.3 \mathrm{~Hz}$, $4 \mathrm{H}, \mathrm{CH}_{2}$-triaz), 4.57 (d, $J=7.9 \mathrm{~Hz}, 2 \mathrm{H}, \mathrm{H}-1 \mathrm{Glc}$ ), 4.47 (dd, $J=11.1$, $7.8 \mathrm{~Hz}, 2 \mathrm{H}, \mathrm{H}-6 \mathrm{Glc}), 4.18-4.05$ (m, 6H, H-6' Glc and H-6 and H-6' (Gal)), 4.04-3.99 ( $\mathrm{m}, 2 \mathrm{H}, \mathrm{H}-4 \mathrm{Gal}), 3.93$ (dd, $J=14.4,8.4 \mathrm{~Hz}, 4 \mathrm{H}, \mathrm{H}-5$ Gal and $\mathrm{H}-5 \mathrm{Glc}$ ), 2.40 (q, $\left.J=7.2 \mathrm{~Hz}, 2 \mathrm{H}, \mathrm{CH}_{2} \mathrm{CH}_{3}\right), 2.19-1.92(\mathrm{~m}$, $42 \mathrm{H}, \mathrm{OAC} x 14), 1.81(\mathrm{~s}, 3 \mathrm{H}), 1.19\left(\mathrm{t}, J=7.5 \mathrm{~Hz}, 2 \mathrm{H}, \mathrm{CH}_{2} \mathrm{CH}_{3}\right) .{ }^{13} \mathrm{C} \mathrm{NMR}$ $\left(125 \mathrm{MHz}, \mathrm{CDCl}_{3}\right): \delta 173.1\left(\mathrm{COC}_{2} \mathrm{H}_{5}\right), 170.4$ ( $\mathrm{CO}$ of OAc), 170.1 (CO of OAc), 170.1 (CO of OAc), 169.6 (CO of OAc), 169.5 (CO of OAc), 169.1 (CO of OAc), 166.6 ( $\mathrm{CONHCH}_{2}$-triaz), 145.6 (C-triaz), 138.9 ( $\left.\mathrm{Ar}-\mathrm{C}\right)$, 134.7 ( $\mathrm{Ar}-\mathrm{C}), 121.5(\mathrm{CH}-\mathrm{triaz}), 121.2(\mathrm{Ar}-\mathrm{CH}), 120.7(\mathrm{Ar}-\mathrm{CH}), 101.1$
(C-1 Glc), 85.5 (C-1 Gal), 76.0 (C-5 Gal), 75.6 (C-4 Gal), 72.6 (C-3 Gal), 70.9 (C-3 Glc), 70.8 (C-2 Gal), 70.7 (C-5 Glc), 69.1 (C-2 Glc), 66.7 (C-4 Glc), 61.9 (C-6 Glc), 60.8 (C-6 Gal), 35.5 ( $\mathrm{CH}_{2}$-triaz), 30.4 $\left(\mathrm{CH}_{2} \mathrm{CH}_{3}\right), 20.7\left(\mathrm{CH}_{3}\right.$ of $\left.\mathrm{OAc}\right), 20.6\left(\mathrm{CH}_{3}\right.$ of $\left.\mathrm{OAc}\right), 20.6\left(\mathrm{CH}_{3}\right.$ of $\left.\mathrm{OAc}\right)$, $20.5\left(\mathrm{CH}_{3}\right.$ of OAc), $20.4\left(\mathrm{CH}_{3}\right.$ of OAc), 20.3, $9.5\left(\mathrm{CH}_{2} \mathrm{CH}_{3}\right)$. IR (film on $\mathrm{NaCl}$ ): 3293, 2942, 1749, 1656, 1599, $1537 \mathrm{~cm}^{-1}$. HRMS (ESI+): $\mathrm{m} / \mathrm{z}$ calcd for $\mathrm{C}_{69} \mathrm{H}_{88} \mathrm{~N}_{9} \mathrm{O}_{37}+\mathrm{H}^{+}[\mathrm{M}+\mathrm{H}]^{+}$1634.5281, found 1634.5287.

4.1.3.1. $N, N^{\prime}$-di-( $\beta$-D-galactopyranosyl-1,2,3-triazol-4ylmethylamide)- $N^{\prime \prime}$-propyl-5-aminobenzene-1,3-dicarboxamide (2a). White amorphous solid (60 mg, 94\%). $[\alpha]_{\mathrm{D}}^{25}+12.7\left(\mathrm{c} 0.5, \mathrm{H}_{2} \mathrm{O}\right) .{ }^{1} \mathrm{H}$ NMR (500 MHz, $\left.\mathrm{D}_{2} \mathrm{O}\right): \delta 8.24(\mathrm{~s}, 2 \mathrm{H}$, triaz-H), $7.85(\mathrm{~s}, 2 \mathrm{H}, \mathrm{Ar}-\mathrm{H}), 7.79$ $(\mathrm{s}, 1 \mathrm{H}, \mathrm{Ar}-\mathrm{H}), 5.66(\mathrm{~d}, J=8.8 \mathrm{~Hz}, 2 \mathrm{H}, \mathrm{H}-1), 4.64\left(\mathrm{~s}, 4 \mathrm{H}, \mathrm{CH}_{2}\right.$-triaz), $4.20(\mathrm{t}, J=9.2 \mathrm{~Hz}, 2 \mathrm{H}, \mathrm{H}-2), 4.08(\mathrm{~d}, J=8.6 \mathrm{~Hz}, 2 \mathrm{H}, \mathrm{H}-4), 3.97(\mathrm{~s}, 2 \mathrm{H}$, $\mathrm{H}-5), 3.86(\mathrm{~d}, J=9.7 \mathrm{~Hz}, 2 \mathrm{H}, \mathrm{H}-3), 3.75(\mathrm{~d}, J=4.7 \mathrm{~Hz}, 2 \mathrm{H}, \mathrm{H}-6$ and $\mathrm{H}-$ $\left.6^{4}\right), 2.37$ (d, $\left.J=7.4 \mathrm{~Hz}, 2 \mathrm{H}, \mathrm{CH}_{2} \mathrm{CH}_{3}\right), 1.12\left(\mathrm{t}, J=7.3 \mathrm{~Hz}, 3 \mathrm{H}, \mathrm{CH}_{2} \mathrm{CH}_{3}\right)$. ${ }^{13} \mathrm{C}$ NMR $\left(125 \mathrm{MHz}, \mathrm{D}_{2} \mathrm{O}\right): \delta 176.8\left(\mathrm{COC}_{2} \mathrm{H}_{5}\right), 169.0\left(\mathrm{CONHCH}_{2}\right.$-triaz), 145.2 (C-triaz), 138.2, 134.6 ( $\mathrm{Ar}-\mathrm{C}), 123.0$ (CH-triaz), 122.9, 122.1 ( $\mathrm{Ar}-\mathrm{CH}), 88.1$ (C-1), 78.3 (C-5), 72.9 (C-3), $69.8(\mathrm{C}-2), 68.6(\mathrm{C}-4)$, 60.9 (C-6), $35.1\left(\mathrm{CH}_{2}\right.$-triaz), $29.9\left(\mathrm{CH}_{2} \mathrm{CH}_{3}\right), 9.2\left(\mathrm{CH}_{2} \mathrm{CH}_{3}\right)$. IR ( $\left.\mathrm{KBr}\right)$ : 3368, 2940, 2121, 1649, 1598, $1546 \mathrm{~cm}^{-1}$. HRMS (ESI+): $\mathrm{m} / z$ calcd. for $\mathrm{C}_{29} \mathrm{H}_{40} \mathrm{~N}_{9} \mathrm{O}_{13}+\mathrm{H}^{+}[\mathrm{M}+\mathrm{H}]+722.2746$, found 722.2730 .

4.1.3.1. $N, N^{\prime}-d i$-( $\beta$-L-fucopyranosyl-1,2,3-triazol-4-ylmethylamide)$N^{\prime \prime}$-propyl-5-aminobenzene-1,3-dicarboxamide (2b). Pale yellow amorphous solid (76 mg, 92\%). $[\alpha]_{\mathrm{D}}^{23}+4.3$ (c $\left.0.4, \mathrm{H}_{2} \mathrm{O}\right) .{ }^{1} \mathrm{H}$ NMR $\left(500 \mathrm{MHz}, \mathrm{D}_{2} \mathrm{O}\right): \delta 8.22(\mathrm{~d}, J=4.1 \mathrm{~Hz}, 2 \mathrm{H}$, triaz-H), $7.88(\mathrm{~d}, J=1.5 \mathrm{~Hz}$, $2 \mathrm{H}, \mathrm{Ar}-\mathrm{H}), 7.81(\mathrm{~s}, 1 \mathrm{H}, \mathrm{Ar}-\mathrm{H}), 5.65-5.61$ (d, $J=9.2 \mathrm{~Hz}, 2 \mathrm{H}, \mathrm{H}-1)$, $4.65\left(\mathrm{~s}, 4 \mathrm{H}, \mathrm{CH}_{2}\right.$-triaz), $4.15(\mathrm{t}, J=9.5 \mathrm{~Hz}, 2 \mathrm{H}, \mathrm{H}-2), 4.08-4.02(\mathrm{~m}, 2 \mathrm{H}$, $\mathrm{H}-5), 3.90-3.82(\mathrm{~m}, 4 \mathrm{H}, \mathrm{H}-3$ and $\mathrm{H}-4), 2.37(\mathrm{q}, J=7.6 \mathrm{~Hz}, 2 \mathrm{H}$, $\left.\mathrm{CH}_{2} \mathrm{CH}_{3}\right), 1.25-1.22\left(\mathrm{~m}, 6 \mathrm{H}, \mathrm{C} 6-\mathrm{H}_{3}\right), 1.12\left(\mathrm{t}, \mathrm{J}=7.6 \mathrm{~Hz}, 3 \mathrm{H}, \mathrm{CH}_{2} \mathrm{CH}_{3}\right)$. ${ }^{13} \mathrm{C} \mathrm{NMR}\left(125 \mathrm{MHz}, \mathrm{D}_{2} \mathrm{O}\right): \delta 176.6\left(\mathrm{COC}_{2} \mathrm{H}_{5}\right), 168.7\left(\mathrm{CONHCH}_{2}\right.$-triaz), 144.8 (C-triaz), $138.2(\mathrm{Ar}-\mathrm{C}), 134.4(\mathrm{Ar}-\mathrm{C}), 123.0$ (CH-triaz), 122.7 $(\mathrm{Ar}-\mathrm{CH}), 121.9(\mathrm{Ar}-\mathrm{CH}), 88.1(\mathrm{C}-1), 74.4(\mathrm{C}-5), 73.1(\mathrm{C}-3), 71.2(\mathrm{C}-4)$, 69.5 (C-2), $35.0\left(\mathrm{CH}_{2}\right.$-triaz), $29.9\left(\mathrm{CH}_{2} \mathrm{CH}_{3}\right), 15.5(\mathrm{C}-6), 9.1\left(\mathrm{CH}_{2} \mathrm{CH}_{3}\right)$. IR (ATR): 3261, 2917, 2851, 1646, 1601, $1536 \mathrm{~cm}^{-1}$. HRMS (ESI+): $m / z$ calcd for $\mathrm{C}_{29} \mathrm{H}_{39} \mathrm{~N}_{9} \mathrm{O}_{11}+\mathrm{H}^{+}[\mathrm{M}+\mathrm{H}]^{+} 690.6910$, found 690.6923 .

4.1.3.1. $N, N^{\prime}-d i-[2-O-(\beta$-D-galactopyranosyl)-ethyl-1,2,3-triazol-4ylmethylamide)- $N^{\prime \prime}$-propyl-5-aminobenzene-1,3-dicarboxamide (2c). Pale brown amorphous solid $(55 \mathrm{mg}, 91 \%)$. $[\alpha]_{\mathrm{D}}^{20}+2.9\left(\mathrm{c} 0.3, \mathrm{H}_{2} \mathrm{O}\right)$. ${ }^{1} \mathrm{H}$ NMR $\left(500 \mathrm{MHz}, \mathrm{D}_{2} \mathrm{O}\right): \delta 8.10(\mathrm{~s}, 2 \mathrm{H}$, triaz-H), $8.00(\mathrm{~d}, J=1.5 \mathrm{~Hz}$, $2 \mathrm{H}, \mathrm{Ar}-\mathrm{H}), 7.93(\mathrm{~s}, 1 \mathrm{H}, \mathrm{Ar}-\mathrm{H}), 4.73-4.67\left(\mathrm{~m}, 8 \mathrm{H}, \mathrm{CH}_{2}\right.$-triaz and $\left.\mathrm{CH}_{2} \mathrm{CH}_{2}\right), 4.39-4.27\left(\mathrm{~m}, 4 \mathrm{H}, \mathrm{H}-1\right.$ and $\left.\mathrm{CHCH}_{2}\right), 4.18-4.10(\mathrm{~m}, 2 \mathrm{H}$, $\mathrm{CHCH}_{2}$ ), 3.90 (dd, $\left.J=3.4,0.8 \mathrm{~Hz}, 2 \mathrm{H}, \mathrm{H}-4\right), 3.77-3.68(\mathrm{~m}, 4 \mathrm{H}, \mathrm{H}-6$ and $\mathrm{H}^{-6} \mathrm{6}^{\mathrm{c}}$ ), 3.68-3.61 (m, 2H, H-5), $3.59(\mathrm{dd}, J=9.9,3.4 \mathrm{~Hz}, 2 \mathrm{H}, \mathrm{H}-3)$, 3.48 (dd, $J=10.0,7.8 \mathrm{~Hz}, 2 \mathrm{H}, \mathrm{H}-2), 2.47$ (q, $J=7.6 \mathrm{~Hz}, 2 \mathrm{H}, \mathrm{CH}_{2} \mathrm{CH}_{3}$ ), $1.20\left(\mathrm{td}, J=7.6,1.6 \mathrm{~Hz}, 3 \mathrm{H}, \mathrm{CH}_{2} \mathrm{CH}_{3}\right) .{ }^{13} \mathrm{C}$ NMR $\left(125 \mathrm{MHz}, \mathrm{D}_{2} \mathrm{O}\right)$ : $\delta 176.8\left(\mathrm{COC}_{2} \mathrm{H}_{5}\right), 168.8\left(\mathrm{CONHCH}_{2}\right.$-triaz $), 144.3$ (C-triaz), 138.1 $(\mathrm{Ar}-\mathrm{C}), 134.6(\mathrm{Ar}-\mathrm{C}), 124.8$ (CH-triaz), $123.0(\mathrm{Ar}-\mathrm{CH}), 122.1$ $(\mathrm{Ar}-\mathrm{CH}), 103.0(\mathrm{C}-1), 75.1$ (C-5), 72.6 (C-3), $70.6(\mathrm{C}-2), 68.5(\mathrm{C}-4)$, 60.9 (C-6), $35.0\left(\mathrm{CH}_{2}\right.$-triaz), $29.9\left(\mathrm{CH}_{2} \mathrm{CH}_{3}\right), 9.2\left(\mathrm{CH}_{2} \mathrm{CH}_{3}\right) . \mathrm{IR}(\mathrm{KBr})$ : 3365, 3323, 3117, 3053, 2977, 2942, 2882, 1691, 1651, 1614, $1564 \mathrm{~cm}^{-1}$. HRMS (ESI+): $m / z$ calcd for $\mathrm{C}_{33} \mathrm{H}_{48} \mathrm{~N}_{9} \mathrm{O}_{15}+\mathrm{H}^{+}[\mathrm{M}+\mathrm{H}]^{+}$ 810.3270 , found 810.3322 .

4.1.3.1. $N, N^{\prime}-d i-(\alpha-D-m a n n o p y r a n o s y l-1,2,3-t r i a z o l-4-$ ylmethylamide)- $N^{\prime \prime}$-propyl-5-aminobenzene-1,3-dicarboxamide (2d). Pale yellow amorphous solid (42 mg, 88\%). $[\alpha]_{\mathrm{D}}^{22}+19.1\left(\mathrm{c} 0.4, \mathrm{H}_{2} \mathrm{O}\right)$. ${ }^{1} \mathrm{H}$ NMR $\left(500 \mathrm{MHz}, \mathrm{D}_{2} \mathrm{O}\right): \delta 8.14(\mathrm{~s}, 2 \mathrm{H}$, triaz-H), $7.85(\mathrm{~s}, 2 \mathrm{H}, \mathrm{Ar}-\mathrm{H})$, $7.78(\mathrm{~s}, 1 \mathrm{H}, \mathrm{Ar}-\mathrm{H}), 6.08$ (s, 2H, H-1), 4.75 (s, 2H, H-2), $4.64(\mathrm{~s}, 4 \mathrm{H}$, $\mathrm{CH}_{2}$-triaz), 4.14 (dd, $\left.J=9.0,3.2 \mathrm{~Hz}, 2 \mathrm{H}, \mathrm{H}-3\right), 3.86-3.74(\mathrm{~m}, 6 \mathrm{H}, \mathrm{H}-4$ and $\mathrm{H}-6$ and $\left.\mathrm{H}-6^{\circ}\right), 3.38-3.29(\mathrm{~m}, 2 \mathrm{H}, \mathrm{H}-5), 2.37(\mathrm{q}, J=7.6 \mathrm{~Hz}, 2 \mathrm{H}$, $\left.\mathrm{CH}_{2} \mathrm{CH}_{3}\right), 1.12\left(\mathrm{t}, J=7.6 \mathrm{~Hz}, 3 \mathrm{H}, \mathrm{CH}_{2} \mathrm{CH}_{3}\right) .{ }^{13} \mathrm{C} \mathrm{NMR}\left(125 \mathrm{MHz}, \mathrm{D}_{2} \mathrm{O}\right)$ : $\delta 176.4\left(\mathrm{COC}_{2} \mathrm{H}_{5}\right), 168.5\left(\mathrm{CONHCH}_{2}\right.$-triaz $), 145.0$ (C-triaz), 138.2 
(Ar-C), $134.4(\mathrm{Ar}-\mathrm{C}), 123.7$ (CH-triaz), $122.4(\mathrm{Ar}-\mathrm{CH}), 121.7$ ( $\mathrm{Ar}-\mathrm{CH}), 86.7$ (C-1), 76.2 (C-5), 70.6 (C-3), 68.3 (C-2), 66.6 (C-4), 60.5 (C-6), $35.0\left(\mathrm{CH}_{2}\right.$-triaz), $29.9\left(\mathrm{CH}_{2} \mathrm{CH}_{3}\right), 9.1\left(\mathrm{CH}_{2} \mathrm{CH}_{3}\right)$. IR $(\mathrm{KBr})$ : $3375,2941,1649,1555 \mathrm{~cm}^{-1}$. HRMS $(\mathrm{ESI}+): \mathrm{m} / \mathrm{z}$ calcd for $\mathrm{C}_{29} \mathrm{H}_{40} \mathrm{~N}_{9} \mathrm{O}_{13}+\mathrm{H}^{+}[\mathrm{M}+\mathrm{H}]^{+}$722.2746, found 722.2740.

4.1.3.1. $N, N^{\prime}$-di-(2-Acetamido-2-deoxy- $\beta$-D-glucopyranosyl-1,2,3triazol-4-ylmethylamide)-1,2,3-triazol-4-ylmethylamide)- $N^{\prime \prime}$-propyl5-aminobenzene-1,3-dicarboxamide (2e). Pale yellow amorphous solid (34 mg, 75\%). [a $]_{\mathrm{D}}^{22}-5.2\left(\mathrm{c} 0.3, \mathrm{H}_{2} \mathrm{O}\right) .{ }^{1} \mathrm{H}$ NMR $\left(500 \mathrm{MHz}, \mathrm{D}_{2} \mathrm{O}\right)$ : $\delta 8.20(\mathrm{~s}, 2 \mathrm{H}$, triaz-H), $8.01(\mathrm{t}, J=3.9 \mathrm{~Hz}, 2 \mathrm{H}, \mathrm{Ar}-\mathrm{H}), 7.96-7.89(\mathrm{~m}$, $1 \mathrm{H}, \mathrm{Ar}-\mathrm{H}), 5.86(\mathrm{~d}, J=9.7 \mathrm{~Hz}, 2 \mathrm{H}, \mathrm{H}-1), 4.72-4.66\left(\mathrm{~m}, 4 \mathrm{H}, \mathrm{CH}_{2^{-}}\right.$ triaz), 4.27 (t, $J=10.0 \mathrm{~Hz}, 2 \mathrm{H}, \mathrm{H}-2), 4.01-3.64(\mathrm{~m}, 10 \mathrm{H}, \mathrm{H}-3, \mathrm{H}-4, \mathrm{H}-$ 5, H-6 and $\left.\mathrm{H}-6^{\prime}\right), 2.48$ (q, $\left.J=7.6 \mathrm{~Hz}, 2 \mathrm{H}, \mathrm{CH}_{2} \mathrm{CH}_{3}\right), 1.79$ (s, 3H, NHAc), $1.21\left(\mathrm{t}, J=7.6 \mathrm{~Hz}, 3 \mathrm{H}, \mathrm{CH}_{2} \mathrm{CH}_{3}\right) .{ }^{13} \mathrm{C}$ NMR $\left(125 \mathrm{MHz}, \mathrm{D}_{2} \mathrm{O}\right): \delta 176.8$ $\left(\mathrm{COC}_{2} \mathrm{H}_{5}\right), 174.1$ (CO of NHAc), $168.9\left(\mathrm{CONHCH}_{2}\right.$-triaz), 123.2 $(\mathrm{Ar}-\mathrm{CH}), 122.8$ (CH-triaz), $122.2(\mathrm{Ar}-\mathrm{CH}), 86.4(\mathrm{C}-1), 78.9(\mathrm{C}-5)$, 73.5 (C-3), 69.3 (C-4), 60.4 (C-6), 55.4 (C-2), 35.0 ( $\mathrm{CH}_{2}$-triaz), 30.0 $\left(\mathrm{CH}_{2} \mathrm{CH}_{3}\right), 21.6\left(\mathrm{CH}_{3}\right.$ of NHAC), $9.2\left(\mathrm{CH}_{2} \mathrm{CH}_{3}\right)$. IR (ATR): 3370, 2943, $1648,1557 \mathrm{~cm}^{-1}$. HRMS (ESI+): $\mathrm{m} / z$ calcd for $\mathrm{C}_{33} \mathrm{H}_{45} \mathrm{~N}_{11} \mathrm{O}_{13}+\mathrm{Na}^{+}$ $[\mathrm{M}+\mathrm{Na}]^{+}$826.3096, found 826.3102.

4.1.3.1. $N, N^{\prime}-d i-[\{4-O-\beta$-D-galactopyranosyl- $\beta$-D-glucopyranosyl $\}$ 1,2,3-triazol-4-ylmethylamide)- $N^{\prime \prime}$-propyl-5-aminobenzene-1,3dicarboxamide (2f). White amorphous $(65 \mathrm{mg}, 90 \%)$. $[\alpha]_{\mathrm{D}}^{17}+1.5$ (c 0.6, $\left.\mathrm{H}_{2} \mathrm{O}\right) .{ }^{1} \mathrm{H}$ NMR $\left(500 \mathrm{MHz}, \mathrm{D}_{2} \mathrm{O}\right): \delta 8.16(\mathrm{~s}, 2 \mathrm{H}$, triaz-H), $7.91(\mathrm{~s}$, $2 \mathrm{H}, \mathrm{Ar}-\mathrm{H}), 7.84(\mathrm{~s}, 1 \mathrm{H}, \mathrm{Ar}-\mathrm{H}), 5.72(\mathrm{~d}, J=9.2 \mathrm{~Hz}, 2 \mathrm{H}, \mathrm{H}-1 \mathrm{Glc}), 4.64$ (s, $4 \mathrm{H}, \mathrm{CH}_{2}$-triaz), 4.45 (d, J = 7.8 Hz, $\left.2 \mathrm{H}, \mathrm{H}-1 \mathrm{Gal}\right), 4.00(\mathrm{t}, J=9.0 \mathrm{~Hz}$, $2 \mathrm{H}, \mathrm{H}-2 \mathrm{Glc}$ ), 3.93-3.87 ( $\mathrm{m}, 3 \mathrm{H}, \mathrm{H}-6 \mathrm{Glc}$ and $\mathrm{H}-4 \mathrm{Gal}$ ), 3.85-3.79 (m, 4H, H-3 Glc, H-4 Glc, H-5 Glc and H-6' Glc), 3.78-3.65 (m, 4H, H-6 Gal, H-6' Gal and H-5 Gal), 3.65-3.57 (m, 2H, H-3 Gal), 3.56-3.49 (m, 2H, H-2 Gal), 2.38 (q, $\left.J=7.6 \mathrm{~Hz}, 1 \mathrm{H}, \mathrm{CH}_{2} \mathrm{CH}_{3}\right), 1.12$ (dd, $J=9.4$, $\left.5.8 \mathrm{~Hz}, 3 \mathrm{H}, \mathrm{CH}_{2} \mathrm{CH}_{3}\right) .{ }^{13} \mathrm{C}$ NMR $\left(125 \mathrm{MHz}, \mathrm{D}_{2} \mathrm{O}\right): \delta 168.8\left(\mathrm{CONHCH}_{2}-\right.$ triaz), 145.0 (C-triaz), 138.2 ( $\mathrm{Ar}-\mathrm{C}), 134.4(\mathrm{Ar}-\mathrm{C}), 123.1$ (CH-triaz), 122.8 ( $\mathrm{Ar}-\mathrm{CH}$ ), 102.8 (C-1 Gal), 87.2 (C-1 Glc), 77.6 (C-4/5 Glc), 77.2 (C-4/5 Glc), 75.3 (C-5 Gal), 74.4 (C-3 Glc), 72.4 (C-3 Gal), 71.9 (C-2 Glc), 70.9 (C-2 Gal), 68.5 (C-4 Gal), 61.0 (C-6 Gal), 59.7 (C-6 Glc), 35.0 ( $\mathrm{CH}_{2}$-triaz), $29.8\left(\mathrm{CH}_{2} \mathrm{CH}_{3}\right), 9.1\left(\mathrm{CH}_{2} \mathrm{CH}_{3}\right)$. IR ( $\left.\mathrm{KBr}\right)$ : 3412, 2923, $2125,1644,1548 \mathrm{~cm}^{-1}$. HRMS (ESI +$): \mathrm{m} / z$ calcd for $\mathrm{C}_{41} \mathrm{H}_{60} \mathrm{~N}_{9} \mathrm{O}_{23}+\mathrm{H}^{+}[\mathrm{M}+\mathrm{H}]^{+}$1046.3802, found 1046.2788.

\subsubsection{1. $\mathrm{N}$-(prop-2-yn-1-yl)-3-propionamidobenzamide}

(9).

3-aminobenzoic acid (2 g, $14.6 \mathrm{mmol})$ was dissolved in anhydrous THF (15 mL) under $\mathrm{N}_{2}$ and propionyl chloride (3.19 mL, $36.5 \mathrm{mmol}$ ) was added dropwise. The mixture was allowed to stir for $5 \mathrm{~min}$ and $\mathrm{NEt}_{3}$ (6.1 mL, $43.8 \mathrm{mmol}$ ) was added slowly. The reaction was left to stir for $16 \mathrm{~h}$. The solvent was removed in vacuo. The crude mixture was dissolved in ethyl acetate $(30 \mathrm{~mL})$, washed with $0.5 \mathrm{M} \mathrm{HCl}$ $(30 \mathrm{~mL})$, and dried $\left(\mathrm{MgSO}_{4}\right)$. The mixture was filtered and the solvent was removed under reduced pressure to yield the product 3(propionylamino) benzoic acid as an off-white amorphous $(0.637 \mathrm{~g}$, $23 \%)$ which was used without further purification. This acid $(0.307 \mathrm{~g}, 1.59 \mathrm{mmol})$ and TBTU $(0.56 \mathrm{~g}, 1.75 \mathrm{mmol})$ were dissolved in anhydrous DMF $(15 \mathrm{~mL})$ under $\mathrm{N}_{2}$. $\mathrm{NEt}_{3}(0.3 \mathrm{~mL}, 2.38 \mathrm{mmol})$ was added, and the reaction mixture was stirred for $10 \mathrm{~min}$ on ice. Propargylamine $(0.15 \mathrm{~mL}, 2.38 \mathrm{mmol})$ was added, and the reaction was stirred for $16 \mathrm{~h}$ at rt. The solvent was removed in vacuo. The crude mixture was dissolved in ethyl acetate $(30 \mathrm{~mL})$, washed with $0.5 \mathrm{M} \mathrm{HCl}(30 \mathrm{~mL})$, sat. $\mathrm{NaHCO}_{3}(30 \mathrm{~mL})$ and brine $(30 \mathrm{~mL})$, and dried $\left(\mathrm{MgSO}_{4}\right)$. The mixture was filtered and the solvent was removed in the rotatory evaporator to yield product 9: pale yellow amorphous $(0.359 \mathrm{~g}, 98 \%) .{ }^{1} \mathrm{H}$ NMR $\left(500 \mathrm{MHz}\right.$, DMSO- $\left.d_{6}\right): \delta 9.99$ (s, $\left.1 \mathrm{H}, \mathrm{NHCH}_{2} \mathrm{CCH}\right), 8.86\left(\mathrm{~s}, 1 \mathrm{H}, \mathrm{NHCOC}_{2} \mathrm{H}_{5}\right), 8.04(\mathrm{~s}, 1 \mathrm{H}, \mathrm{Ar}-\mathrm{H}), 7.77(\mathrm{~d}$, $J=8.2 \mathrm{~Hz}, 1 \mathrm{H}, \mathrm{Ar}-\mathrm{H}), 7.48(\mathrm{~d}, J=7.7 \mathrm{~Hz}, 1 \mathrm{H}, \mathrm{Ar}-\mathrm{H}), 7.37$ (t, $J=7.9 \mathrm{~Hz}, 1 \mathrm{H}, \mathrm{Ar}-\mathrm{H}), 4.03\left(\mathrm{dd}, J=5.5,2.4 \mathrm{~Hz}, 2 \mathrm{H}, \mathrm{CH}_{2} \mathrm{CCH}\right), 3.10(\mathrm{t}$,
$\left.J=2.3 \mathrm{~Hz}, 1 \mathrm{H}, \mathrm{CH}_{2} \mathrm{CCH}\right), 2.32\left(\mathrm{q}, J=7.5 \mathrm{~Hz}, 2 \mathrm{H}, \mathrm{CH}_{2} \mathrm{CH}_{3}\right), 1.08(\mathrm{t}$, $\left.J=7.5 \mathrm{~Hz}, 3 \mathrm{H}, \mathrm{CH}_{2} \mathrm{CH}_{3}\right) .{ }^{13} \mathrm{C}$ NMR $\left(125 \mathrm{MHz}, \mathrm{DMSO}-d_{6}\right): \delta 172.6$ $\left(\mathrm{COC}_{2} \mathrm{H}_{5}\right), 166.4\left(\mathrm{CONHCH}_{2}\right.$-triaz $), 139.9(\mathrm{Ar}-\mathrm{C}), 135.0(\mathrm{Ar}-\mathrm{C}), 129.1$ $(\mathrm{Ar}-\mathrm{CH}), 122.3(\mathrm{Ar}-\mathrm{CH}), 121.8(\mathrm{Ar}-\mathrm{CH}), 118.9(\mathrm{Ar}-\mathrm{CH}), 81.8$ $\left(\mathrm{CH}_{2} \mathrm{CCH}\right), 73.2\left(\mathrm{CH}_{2} \mathrm{CCH}\right), 30.0\left(\mathrm{CH}_{2} \mathrm{CH}_{3}\right), 29.0\left(\mathrm{CH}_{2} \mathrm{CCH}\right), 10.1$ $\left(\mathrm{CH}_{2} \mathrm{CH}_{3}\right.$ ). IR (KBr): 3365, 3321, 3298, 3117, 2977, 2942, 1690, 1652, $1562 \mathrm{~cm}^{-1}$. HRMS (ESI+): $\mathrm{m} / z$ calcd for $\mathrm{C}_{13} \mathrm{H}_{15} \mathrm{~N}_{2} \mathrm{O}_{2}+\mathrm{H}^{+}[\mathrm{M}+\mathrm{H}]^{+}$ 231.1134, found 231.1135 .

4.1.3.1. $N$-(2,3,4,6-tetra-O-acetyl- $\beta$-D-galactopyranosyl-1,2,3-triazol4-ylmethylamide)- $N^{\prime}$-propyl-3-aminobenzene-1-carboxamide (10a). Prepared from 9 to 2,3,4,6-tetra-O-acetyl-1- $\beta$-azido-D-galactopyranoside [34], according to Method A: Off-white amorphous solid (235 mg, 83\%). $\mathrm{R}_{f}=0.45$ (DCM:MeOH 9:1). [ $\left.\alpha\right]_{\mathrm{D}}^{19}-6.9$ (c 0.9, DCM). ${ }^{1} \mathrm{H}$ NMR $\left(500 \mathrm{MHz}, \mathrm{CDCl}_{3}\right): \delta 8.62\left(\mathrm{~s}, 1 \mathrm{H}, \mathrm{NHCOC}_{2} \mathrm{H}_{5}\right), 7.95(\mathrm{~s}, 1 \mathrm{H}$, triaz-H), 7.89-7.78 (m, 2H, $\mathrm{Ar}-\mathrm{H}$ x2), $7.72\left(\mathrm{~s}, 1 \mathrm{H}, \mathrm{NHCH}_{2}\right.$-triaz), 7.48 $(\mathrm{d}, J=7.4 \mathrm{~Hz}, 1 \mathrm{H}, \mathrm{Ar}-\mathrm{H}), 7.28(\mathrm{t}, J=7.8 \mathrm{~Hz}, 1 \mathrm{H}, \mathrm{Ar}-\mathrm{H}), 5.91(\mathrm{~d}$, $J=9.2 \mathrm{~Hz}, 1 \mathrm{H}, \mathrm{H}-1), 5.56(\mathrm{~m}, 2 \mathrm{H}, \mathrm{H}-2$ and $\mathrm{H}-4), 5.34-5.24(\mathrm{~m}, 2 \mathrm{H}, \mathrm{H}-$ 3), $4.68\left(\mathrm{dd}, J=14.5,3.5 \mathrm{~Hz}, 2 \mathrm{H}, \mathrm{CH}_{2}\right.$-triaz), 4.31 (t, $J=6.1 \mathrm{~Hz}, 1 \mathrm{H}, \mathrm{H}-$ 5), 4.15 (dd, $J=11.5,6.8 \mathrm{~Hz}, 2 \mathrm{H}, \mathrm{H}-6$ and H-6'), 2.39 (q, $J=7.4 \mathrm{~Hz}, 2 \mathrm{H}$, $\mathrm{CH}_{2} \mathrm{CH}_{3}$ ), 2.18 (s, 3H, OAc), 2.00 (s, 6H, OAc x2), 1.82 (s, 3H, OAc), 1.18 $\left(\mathrm{t}, J=7.5 \mathrm{~Hz}, 3 \mathrm{H}, \mathrm{CH}_{2} \mathrm{CH}_{3}\right) .{ }^{13} \mathrm{C}$ NMR $\left(125 \mathrm{MHz}, \mathrm{CDCl}_{3}\right): \delta 173.0$ $\left(\mathrm{NHCOC}_{2} \mathrm{H}_{5}\right.$ ), 170.4 (CO of OAc), 170.1 (CO of OAc), 169.9 (CO of OAc),

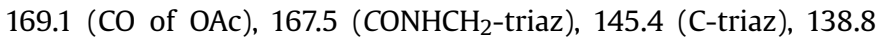
$(\mathrm{Ar}-\mathrm{C}), 134.5(\mathrm{Ar}-\mathrm{C}), 129.1(\mathrm{Ar}-\mathrm{CH}), 123.1(\mathrm{Ar}-\mathrm{CH}), 122.3(\mathrm{Ar}-\mathrm{CH})$, 121.6 (CH-triaz), $118.5(\mathrm{Ar}-\mathrm{CH}), 86.1$ (C-1), 73.9 (C-5), 70.8 (C-3), 68.0 (C-2), 66.9 (C-4), 61.2 (C-6), $35.3\left(\mathrm{CH}_{2}\right.$-triaz), $30.4\left(\mathrm{CH}_{2} \mathrm{CH}_{3}\right)$, $20.6\left(\mathrm{CH}_{3}\right.$ of $\left.\mathrm{OAc}\right), 20.6\left(\mathrm{CH}_{3}\right.$ of $\left.\mathrm{OAc}\right), 20.5\left(\mathrm{CH}_{3}\right.$ of $\left.\mathrm{OAc}\right), 20.2\left(\mathrm{CH}_{3}\right.$ of OAc), $9.6\left(\mathrm{CH}_{2} \mathrm{CH}_{3}\right)$. IR (film on $\mathrm{NaCl}$ ): 3311, 2980, 1753, 1652, 1591, $1553 \mathrm{~cm}^{-1}$. HRMS (ESI + ): $m / z$ calcd for $\mathrm{C}_{27} \mathrm{H}_{34} \mathrm{~N}_{5} \mathrm{O}_{11}+\mathrm{H}^{+}[\mathrm{M}+\mathrm{H}]^{+}$ 604.2255 , found 604.2262 .

4.1.3.1. $N$-(2,3,4-tri-O-acetyl- $\beta$-L-fucopyranosyl-1,2,3-triazol-4ylmethylamide)- $N^{\prime}$-propyl-3-aminobenzene-1-carboxamide (10b). Prepared from 9 to 2,3,4-tri-O-acetyl-1- $\beta$-azido-L-fucopyranoside [41] according to Method A: Off-white amorphous solid (90 mg, 76\%). $\mathrm{R}_{f}=0.56$ (DCM:MeOH 9:1). $[\alpha]_{\mathrm{D}}^{20}:+16.1$ (c 1, DCM). ${ }^{1} \mathrm{H}$ NMR $\left(500 \mathrm{MHz}, \mathrm{CDCl}_{3}\right): \delta 8.32\left(\mathrm{~s}, 1 \mathrm{H}, \mathrm{NHCOC}_{2} \mathrm{H}_{5}\right), 7.90(\mathrm{~s}, 1 \mathrm{H}$, triaz-H), $7.87(\mathrm{~d}, J=8.0 \mathrm{~Hz}, 1 \mathrm{H}, \mathrm{Ar}-\mathrm{H}), 7.77(\mathrm{~s}, 1 \mathrm{H}, \mathrm{Ar}-\mathrm{H}), 7.46(\mathrm{~m}, 2 \mathrm{H}$, $\mathrm{Ar}-\mathrm{H}$ and $\mathrm{NHCH}_{2}$-triaz), $7.28(\mathrm{t}, J=8.0 \mathrm{~Hz}, 1 \mathrm{H}, \mathrm{Ar}-\mathrm{H}), 5.78(\mathrm{~d}$, $J=9.2 \mathrm{~Hz}, 1 \mathrm{H}, \mathrm{H}-1), 5.52-5.46(\mathrm{~m}, 1 \mathrm{H}, \mathrm{H}-2), 5.35$ (d, $J=2.9 \mathrm{~Hz}, 1 \mathrm{H}$, $\mathrm{H}-4), 5.24$ (dd, $J=10.3,3.4 \mathrm{~Hz}, 1 \mathrm{H}, \mathrm{H}-3$ ), 4.66 (dd, $J=15.2,5.6 \mathrm{~Hz}$, $2 \mathrm{H}, \mathrm{CH}_{2}$-triaz), 4.11 (q, $\left.J=6.4 \mathrm{~Hz}, 1 \mathrm{H}, \mathrm{H}-5\right), 2.37$ (q, $J=7.5 \mathrm{~Hz}, 2 \mathrm{H}$, $\mathrm{CH}_{2} \mathrm{CH}_{3}$ ), 2.20 (s, 3H, OAc), 1.97 (s, 3H, OAc), 1.81 (s, 3H, OAc), 1.26-1.13 (m, 6H, C6- $\mathrm{H}_{3}$ and $\left.\left.\mathrm{CH}_{2} \mathrm{CH}_{3}\right) .{ }^{13} \mathrm{C} \mathrm{NMR} \mathrm{(125} \mathrm{MHz,} \mathrm{CDCl}_{3}\right)$ : $\delta 171.8\left(\mathrm{COC}_{2} \mathrm{H}_{5}\right), 169.5$ (CO of OAc), 168.9 (CO of OAc), 168.2 (CO of OAc), 166.4 ( $\mathrm{CONHCH}_{2}$-triaz), 144.3 ( $\mathrm{CH}$-triaz), 137.8 ( $\left.\mathrm{Ar}-\mathrm{C}\right), 133.6$ $(\mathrm{Ar}-\mathrm{C}), 128.2(\mathrm{Ar}-\mathrm{CH}), 122.1(\mathrm{Ar}-\mathrm{CH}), 121.4(\mathrm{Ar}-\mathrm{CH}), 120.4(\mathrm{CH}-$ triaz), 117.4 ( $\mathrm{Ar}-\mathrm{CH}), 85.3$ (C-1), 71.7 (C-5), 70.2 (C-3), 68.9 (C-4), 67.2 (C-2), $34.4\left(\mathrm{CH}_{2}\right.$-triaz), $29.5\left(\mathrm{CH}_{2} \mathrm{CH}_{3}\right), 19.7\left(\mathrm{CH}_{3}\right.$ of $\left.\mathrm{OAc}\right), 19.5$ $\left(\mathrm{CH}_{3}\right.$ of OAc), $19.3\left(\mathrm{CH}_{3}\right.$ of OAc), $15.0(\mathrm{C}-6), 8.6\left(\mathrm{CH}_{2} \mathrm{CH}_{3}\right)$. IR (film on $\mathrm{NaCl})$ : 3308, 3146, 3085, 2985, 2941, 2248, 1750, 1647, 1591, $1553 \mathrm{~cm}^{-1}$. HRMS (ESI+): $\mathrm{m} / z$ calcd for $\mathrm{C}_{25} \mathrm{H}_{32} \mathrm{~N}_{5} \mathrm{O}_{9}+\mathrm{H}^{+}[\mathrm{M}+\mathrm{H}]^{+}$ 546.2200, found 546.2197.

4.1.3.1. $N$-[2-O-(2,3,4,6-tetra-O-acetyl- $\beta$-D-galactopyranosyl)-ethyl1,2,3-triazol-4-ylmethylamide)- $N^{\prime}$-propyl-3-aminobenzene-1carboxamide (10c). Prepared from 9 and 2-O-(2,3,4,6-tetra-Oacetyl- $\beta$-D-galactopyranosyl)ethyl azide [42] according to Method A: Off-white amorphous solid (97 mg, 88\%). $\mathrm{R}_{f}=0.36$ (DCM:MeOH 9:1). $[\alpha]_{\mathrm{D}}^{23}-3.1$ (c 1, DCM). ${ }^{1} \mathrm{H}$ NMR $\left(500 \mathrm{MHz}, \mathrm{CDCl}_{3}\right): \delta 8.41(\mathrm{~s}, 1 \mathrm{H}$, $\left.\mathrm{NHCOC}_{2} \mathrm{H}_{5}\right), 7.90(\mathrm{~d}, J=8.0 \mathrm{~Hz}, 1 \mathrm{H}, \mathrm{Ar}-\mathrm{H}), 7.80(\mathrm{~s}, 1 \mathrm{H}, \mathrm{Ar}-\mathrm{H}), 7.63(\mathrm{~s}$, $1 \mathrm{H}$, triaz- $H), 7.56\left(\mathrm{t}, J=5.1 \mathrm{~Hz}, 1 \mathrm{H}, \mathrm{NHCH}_{2}\right.$-triaz), $7.46(\mathrm{~d}, J=7.7 \mathrm{~Hz}$, $1 \mathrm{H}, \mathrm{Ar}-H), 7.27(\mathrm{t}, J=8 \mathrm{~Hz}, 1 \mathrm{H}, \mathrm{Ar}-H), 5.34(\mathrm{dd}, J=3.4,1.0 \mathrm{~Hz}, 1 \mathrm{H}$, $\mathrm{H}-4$ ), 5.11 (dd, $J=12.5,6.2 \mathrm{~Hz}, 1 \mathrm{H}, \mathrm{H}-2), 4.96$ (dd, $J=10.5,3.4 \mathrm{~Hz}, 1 \mathrm{H}$, 
$\mathrm{H}-3$ ), 4.69-4.59 (m, 2H, CH -triaz), 4.56-4.44 (m, $\left.2 \mathrm{H}, \mathrm{CH}_{2} \mathrm{CH}_{2} \mathrm{O}\right)$, $4.42(\mathrm{~d}, \mathrm{~J}=7.9,1 \mathrm{H}, \mathrm{H}-1), 4.18$ (dt, $J=10.5,4.1 \mathrm{~Hz}, 1 \mathrm{H}, \mathrm{CHO}-\mathrm{Gal}), 4.08$ (dd, $J=11.3,6.6 \mathrm{~Hz}, 2 \mathrm{H}, \mathrm{H}-6$ and H-6 $)$, 3.95-3.85 (m, 2H, CHO-Gal and $\mathrm{H}-5$ ), 2.36 (q, $J=7.5 \mathrm{~Hz}, 2 \mathrm{H}, \mathrm{CH}_{2} \mathrm{CH}_{3}$ ), 2.09 (s, 3H, OAc), 1.99 (s, $3 \mathrm{H}, \mathrm{OAc}), 1.93$ (s, 3H, OAc), 1.90 (s, 3H, OAc), $1.16(\mathrm{t}, J=7.6 \mathrm{~Hz}, 3 \mathrm{H}$, $\left.\mathrm{CH}_{2} \mathrm{CH}_{3}\right) \cdot{ }^{13} \mathrm{C}$ NMR $\left(125 \mathrm{MHz}, \mathrm{CDCl}_{3}\right): \delta 172.8\left(\mathrm{COC}_{2} \mathrm{H}_{5}\right), 170.4(\mathrm{CO}$ of OAc), 170.2 (CO of OAc), 170.0 (CO of OAc), 169.7 (CO of OAc), 167.3 ( $\mathrm{CONHCH}_{2}$-triaz), 144.5 (C-triaz), 138.9 ( $\left.\mathrm{Ar}-\mathrm{C}\right), 134.6(\mathrm{Ar}-\mathrm{C}), 129.1$ (Ar-CH), 123.8 (CH-triaz), $123.0(\mathrm{Ar}-\mathrm{CH}), 122.2(\mathrm{Ar}-\mathrm{CH}), 118.5$ $(\mathrm{Ar}-\mathrm{CH}), 100.9$ (C-1), 70.9 (C-5), $70.6(\mathrm{C}-3), 68.6(\mathrm{C}-2), 67.5$ $\left(\mathrm{CH}_{2} \mathrm{CH}_{2} \mathrm{O}-\mathrm{Gal}\right), 66.9$ (C-4), $61.2(\mathrm{C}-6), 50.1\left(\mathrm{CH}_{2} \mathrm{CH}_{2} \mathrm{O}-\mathrm{Gal}\right), 35.5$ $\left(\mathrm{CH}_{2}\right.$-triaz), $30.5\left(\mathrm{CH}_{2} \mathrm{CH}_{3}\right), 20.6\left(\mathrm{CH}_{3}\right.$ of $\left.\mathrm{OAc}\right), 20.6\left(\mathrm{CH}_{3}\right.$ of $\left.\mathrm{OAc}\right)$, $20.6\left(\mathrm{CH}_{3}\right.$ of OAc), $20.5\left(\mathrm{CH}_{3}\right.$ of OAc), $9.6\left(\mathrm{CH}_{2} \mathrm{CH}_{3}\right)$. IR (film on $\left.\mathrm{NaCl}\right)$ : 3312, 3146, 2980, 2941, 2250, 2111, 1750, 1649, 1591, $1552 \mathrm{~cm}^{-1}$. HRMS (ESI+): $m / z$ calcd for $\mathrm{C}_{29} \mathrm{H}_{37} \mathrm{~N}_{5} \mathrm{O}_{12}+\mathrm{H}^{+}[\mathrm{M}+\mathrm{H}]^{+}$648.2517, found 648.2581 .

4.1.3.1. $N-\left(\beta\right.$-D-galactopyranosyl-1,2,3-triazol-4-ylmethylamide)- $N^{\prime}-$ propyl-3-aminobenzene-1-carboxamide (1a). White amorphous solid (73 mg, 92\%). $[\alpha]_{D}^{19}+11.6\left(\right.$ c $\left.0.7, \mathrm{H}_{2} \mathrm{O}\right) .{ }^{1} \mathrm{H}$ NMR $\left(500 \mathrm{MHz}, \mathrm{D}_{2} \mathrm{O}\right)$ : $\delta 8.09(\mathrm{~s}, 1 \mathrm{H}$, triaz-H), $7.55(\mathrm{t}, J=1.8 \mathrm{~Hz}, 1 \mathrm{H}, \mathrm{Ar}-\mathrm{H}), 7.34(\mathrm{ddd}, J=8.0$, 2.1, $1.0 \mathrm{~Hz}, 1 \mathrm{H}, \mathrm{Ar}-\mathrm{H}), 7.32-7.29(\mathrm{~m}, 1 \mathrm{H}, \mathrm{Ar}-\mathrm{H}), 7.21(\mathrm{t}, J=7.9 \mathrm{~Hz}$, $1 \mathrm{H}, \mathrm{Ar}-\mathrm{H}$ ), 5.53 (d, J=9.2 Hz, $1 \mathrm{H}, \mathrm{H}-1), 4.48$ (s, $2 \mathrm{H}, \mathrm{CH}_{2}$-triaz), 4.07 (t, $J=9.5 \mathrm{~Hz}, 1 \mathrm{H}, \mathrm{H}-2$ ), 3.93 (dd, $J=3.3,0.6 \mathrm{~Hz}, 1 \mathrm{H}, \mathrm{H}-4$ ), 3.83 (td, $J=6.0,0.8 \mathrm{~Hz}, 1 \mathrm{H}, \mathrm{H}-5), 3.72$ (dd, $J=9.8,3.3 \mathrm{~Hz}, 1 \mathrm{H}, \mathrm{H}-3), 3.62$ (d, $J=6.1 \mathrm{~Hz}, 2 \mathrm{H}, \mathrm{H}-6$ and $\left.\mathrm{H}-6^{c}\right), 2.24-2.18\left(\mathrm{q}, J=7.7 \mathrm{~Hz}, 2 \mathrm{H}, \mathrm{CH}_{2} \mathrm{CH}_{3}\right)$, $0.99\left(\mathrm{t}, J=7.6 \mathrm{~Hz}, 3 \mathrm{H}, \mathrm{CH}_{2} \mathrm{CH}_{3}\right) .{ }^{13} \mathrm{C}$ NMR $\left(125 \mathrm{MHz}, \mathrm{D}_{2} \mathrm{O}\right): \delta 176.5$ $\left(\mathrm{NHCOC}_{2} \mathrm{H}_{5}\right), 169.7\left(\mathrm{CONHCH}_{2}\right.$-triaz), 145.0 (C-triaz), $137.5(\mathrm{Ar}-\mathrm{C})$, $133.7(\mathrm{Ar}-\mathrm{C}), 129.4(\mathrm{Ar}-\mathrm{CH}), 124.8(\mathrm{Ar}-\mathrm{CH}), 123.5(\mathrm{Ar}-\mathrm{CH}), 123.1$ (CH-triaz), $119.8(\mathrm{Ar}-\mathrm{CH}), 88.2(\mathrm{C}-1), 78.3(\mathrm{C}-5), 72.9(\mathrm{C}-3), 69.8$ (C2), 68.6 (C-4), 60.9 (C-6), $34.9\left(\mathrm{CH}_{2}\right.$-triaz), $29.8\left(\mathrm{CH}_{2} \mathrm{CH}_{3}\right), 9.2$ $\left(\mathrm{CH}_{2} \mathrm{CH}_{3}\right.$ ). IR (ATR): $3268,1643,1588,1542 \mathrm{~cm}^{-1}$. HRMS (ESI+): $\mathrm{m} / z$ calcd for $\mathrm{C}_{19} \mathrm{H}_{26} \mathrm{~N}_{5} \mathrm{O}_{7}+\mathrm{H}^{+}[\mathrm{M}+\mathrm{H}]^{+}$436.1882, found 436.1826 .

4.1.3.1. $N$-( $\beta$-L-fucopyranosyl-1,2,3-triazol-4-ylmethylamide)- $N^{\prime}$-propyl-3-aminobenzene-1-carboxamide $(\mathbf{1 b})$. Yellow amorphous solid (63 mg, 94\%). [ $\alpha]_{\mathrm{D}}^{23}-6.3$ (c 0.6, $\left.\mathrm{H}_{2} \mathrm{O}\right) .{ }^{1} \mathrm{H}$ NMR (500 MHz, DMSO-d $d_{6}$ ): $\delta 10.02\left(\mathrm{~s}, 1 \mathrm{H}, \mathrm{NHCOC}_{2} \mathrm{H}_{5}\right), 9.01\left(\mathrm{t}, J=5.6 \mathrm{~Hz}, 1 \mathrm{H}, \mathrm{NHCH}_{2}\right.$-triaz), 8.07 $(\mathrm{m}, 2 \mathrm{H}$, triaz-H and $\mathrm{Ar}-\mathrm{H}), 7.82(\mathrm{~d}, J=8.2 \mathrm{~Hz}, 1 \mathrm{H}, \mathrm{Ar}-\mathrm{H}), 7.56(\mathrm{~d}$, $J=7.7 \mathrm{~Hz}, 1 \mathrm{H}, \mathrm{Ar}-\mathrm{H}), 7.40(\mathrm{t}, J=7.9 \mathrm{~Hz}, 1 \mathrm{H}, \mathrm{Ar}-\mathrm{H}), 5.47$ (d, $J=9.2 \mathrm{~Hz}, 1 \mathrm{H}, \mathrm{H}-1), 5.20$ (d, $J=5.9 \mathrm{~Hz}, 1 \mathrm{H}, \mathrm{OH}), 4.96(\mathrm{~d}, J=5.4 \mathrm{~Hz}$, $1 \mathrm{H}, \mathrm{OH}), 4.67(\mathrm{~d}, J=5.7 \mathrm{~Hz}, 1 \mathrm{H}, \mathrm{OH}), 4.61-4.49\left(\mathrm{~m}, 2 \mathrm{H}, \mathrm{CH}_{2}\right.$-triaz), 3.99 (dd, $J=15.0,9.1 \mathrm{~Hz}, 1 \mathrm{H}, \mathrm{H}-2$ ), 3.89 (q, $J=6.4 \mathrm{~Hz}, 1 \mathrm{H}, \mathrm{H}-5), 3.56$ $(\mathrm{m}, 2 \mathrm{H}, \mathrm{H}-3$ and $\mathrm{H}-4), 2.36\left(\mathrm{q}, J=7.6 \mathrm{~Hz}, 2 \mathrm{H}, \mathrm{CH}_{2} \mathrm{CH}_{3}\right), 1.16$ (d, $\left.J=6.4 \mathrm{~Hz}, 3 \mathrm{H}, \mathrm{C} 6-\mathrm{H}_{3}\right), 1.12\left(\mathrm{t}, J=7.5 \mathrm{~Hz}, 3 \mathrm{H}, \mathrm{CH}_{2} \mathrm{CH}_{3}\right) .{ }^{13} \mathrm{C} \mathrm{NMR}$ $\left(125 \mathrm{MHz}, \mathrm{DMSO}-\mathrm{d}_{6}\right): \delta 172.6\left(\mathrm{COC}_{2} \mathrm{H}_{5}\right), 166.7\left(\mathrm{CONHCH}_{2}\right.$-triaz$)$, 145.6 (C-triaz), 139.9 ( $\mathrm{Ar}-\mathrm{C}), 135.3(\mathrm{Ar}-\mathrm{C}), 129.1(\mathrm{Ar}-\mathrm{CH}), 122.3$ $(\mathrm{Ar}-\mathrm{CH}), 122.0(\mathrm{Ar}-\mathrm{CH}), 122.0(\mathrm{CH}-\mathrm{triaz}), 119.0(\mathrm{Ar}-\mathrm{CH}), 88.5(\mathrm{C}-1)$, 74.4 (C-3), 73.7 (C-5), 71.6 (C-4), 69.5 (C-2), $35.4\left(\mathrm{CH}_{2}\right.$-triaz), 30.0 $\left(\mathrm{CH}_{2} \mathrm{CH}_{3}\right), 16.9$ (C-6), $10.1\left(\mathrm{CH}_{2} \mathrm{CH}_{3}\right)$. IR (KBr): 3401, 2925, 1645 , $1589,1542 \mathrm{~cm}^{-1}$. HRMS (ESI + ): $m / z$ calcd for $\mathrm{C}_{19} \mathrm{H}_{25} \mathrm{~N}_{7} \mathrm{O}_{7}+\mathrm{H}^{+}$ $[\mathrm{M}+\mathrm{H}]^{+}$436.1832, found 436.1849 .

4.1.3.1. $N$-[2-O-( $\beta$-D-galactopyranosyl)-ethyl-1,2,3-triazol-4ylmethylamide)- $N^{\prime}$-propyl-3-aminobenzene-1-carboxamide (1c). Off-white amorphous solid (104 mg, 87\%). $[\alpha]_{\mathrm{D}}^{24}+3.8$ (c 1, MeOH). ${ }^{1} \mathrm{H}$ NMR (500 MHz, $\left.\mathrm{D}_{2} \mathrm{O}\right): \delta 8.00(\mathrm{~s}, 1 \mathrm{H}$, triaz-H), $7.75(\mathrm{~s}, 1 \mathrm{H}, \mathrm{Ar}-\mathrm{H})$, $7.56-7.53(\mathrm{~m}, 2 \mathrm{H}, \mathrm{Ar}-\mathrm{H}), 7.40(\mathrm{t}, J=7.8 \mathrm{~Hz}, 1 \mathrm{H}, \mathrm{Ar}-\mathrm{H}), 4.50-4.46$ ( $\mathrm{m}, 4 \mathrm{H}, \mathrm{CH}_{2}$-triaz and $\left.\mathrm{CH}_{2} \mathrm{CH}_{2}\right), 4.29-4.20\left(\mathrm{~m}, 2 \mathrm{H}, \mathrm{H}-1\right.$ and $\left.\mathrm{CHCH}_{2}\right)$, 4.15-4.10 (m, $\left.1 \mathrm{H}, \mathrm{CHCH}_{2}\right), 3.89(\mathrm{~s}, 1 \mathrm{H}, \mathrm{H}-4), 3.80-3.40(\mathrm{~m}, 5 \mathrm{H}, \mathrm{H}-6$, $\mathrm{H}-6{ }^{\prime}, \mathrm{H}-2, \mathrm{H}-3$ and $\left.\mathrm{H}-5\right), 2.33\left(\mathrm{~s}, 2 \mathrm{H}, \mathrm{CH}_{2} \mathrm{CH}_{3}\right), 1.08$ (s, $\left.3 \mathrm{H}, \mathrm{CH}_{2} \mathrm{CH}_{3}\right)$. ${ }^{13} \mathrm{C} \mathrm{NMR}\left(125 \mathrm{MHz}, \mathrm{D}_{2} \mathrm{O}\right) \delta 176.9\left(\mathrm{COC}_{2} \mathrm{H}_{5}\right), 168.8\left(\mathrm{CONHCH}_{2}\right.$-triaz), 144.4 (C-triaz), 137.3 ( $\mathrm{Ar}-\mathrm{C}), 134.0(\mathrm{Ar}-\mathrm{C}), 130.7(\mathrm{Ar}-\mathrm{CH}), 129.6$, $127.8(\mathrm{Ar}-\mathrm{CH}), 126.6(\mathrm{Ar}-\mathrm{CH}), 125.2$ (CH-triaz), 123.8, 122.1 $(\mathrm{Ar}-\mathrm{CH}), 103.0(\mathrm{C}-1), 75.1$ (C-5), $72.6(\mathrm{C}-3), 70.6(\mathrm{C}-2), 68.5(\mathrm{C}-4)$,
$67.8\left(\mathrm{CH}_{2} \mathrm{CH}_{2}\right), 60.9$ (C-6), $50.8\left(\mathrm{CH}_{2} \mathrm{CH}_{2}\right), 34.8\left(\mathrm{CH}_{2}\right.$-triaz), 29.8 $\left(\mathrm{CH}_{2} \mathrm{CH}_{3}\right), 9.3\left(\mathrm{CH}_{2} \mathrm{CH}_{3}\right)$. IR $(\mathrm{KBr}): 3400,2934,2615,1648,1590$, $1549 \mathrm{~cm}^{-1}$. HRMS (ESI+): $\mathrm{m} / z$ calcd for $\mathrm{C}_{21} \mathrm{H}_{29} \mathrm{~N}_{5} \mathrm{O}_{8}+\mathrm{H}^{+}[\mathrm{M}+\mathrm{H}]^{+}$ 480.2094, found 480.2107 .

4.1.3.1. $N, N^{\prime}, N^{\prime \prime}$-tri-(2,3,4,-tri-O-acetyl- $\beta$-L-fucopyranosyl-1,2,3triazol-4-ylmethylamide)-benzene-1,3,5-tricarboxamide

(12b). Prepared from 11 [46] and 2,3,4-tri-O-acetyl-1- $\beta$-azido-L-fucopyranoside [41] according to Method A: yellow amorphous solid (93 mg, 72\%). $[\alpha]_{\mathrm{D}}^{20}+24.7$ (c 0.9, DCM). ${ }^{1} \mathrm{H} \mathrm{NMR}\left(500 \mathrm{MHz}, \mathrm{CDCl}_{3}\right)$ : $\delta 8.22(\mathrm{~s}, 3 \mathrm{H}, \mathrm{Ar}-\mathrm{H}), 8.06\left(\mathrm{~s}, 3 \mathrm{H}, \mathrm{NHCH}_{2}\right.$-triaz), $8.00(\mathrm{~s}, 3 \mathrm{H}$, triaz-H), 5.89 (d, $J=9.2 \mathrm{~Hz}, 3 \mathrm{H}, \mathrm{H}-1), 5.55(\mathrm{t}, J=9.7 \mathrm{~Hz}, 3 \mathrm{H}, \mathrm{H}-2), 5.36$ (d, $J=3.0 \mathrm{~Hz}, 3 \mathrm{H}, \mathrm{H}-4), 5.25$ (dd, $J=10.2,3.3 \mathrm{~Hz}, 3 \mathrm{H}, \mathrm{H}-3$ ), 4.68 (dd, $J=58.5,10.9 \mathrm{~Hz}, 6 \mathrm{H}, \mathrm{CH}_{2}$-triaz), 4.17 (q, $J=6.2 \mathrm{~Hz}, 3 \mathrm{H}, \mathrm{H}-5$ ), 2.21 (s, 9H, OAc), 1.98 (s, 9H, OAc), 1.77 (s, 9H, OAc), 1.21 (d, $J=6.3 \mathrm{~Hz}, 9 \mathrm{H}$, $\left.\mathrm{C} 6-\mathrm{H}_{3}\right) .{ }^{13} \mathrm{C} \mathrm{NMR}\left(125 \mathrm{MHz}, \mathrm{CDCl}_{3}\right): \delta 169.5$ (CO of OAc), 168.9 (CO of OAc), 168.2 (CO of OAc), 165.1 ( $\mathrm{CONHCH}_{2}$-triaz), 144.4 (C-triaz), 127.7 ( $\mathrm{Ar}-\mathrm{CH}), 120.6$ (CH-triaz), 85.3 (C-1), 71.7 (C-5), 70.2 (C-3), 68.9 (C-4), 67.2 (C-2), $34.4\left(\mathrm{CH}_{2}\right.$-triaz), $19.7\left(\mathrm{CH}_{3}\right.$ of $\left.\mathrm{OAc}\right), 19.6\left(\mathrm{CH}_{3}\right.$ of OAc), 19.3 ( $\mathrm{CH}_{3}$ of OAc), 15.0 (C-6). IR (KBr): 3411, 2989, 2942, $2115,1751,1659,1537 \mathrm{~cm}^{-1}$. HRMS (ESI+): $\mathrm{m} / \mathrm{z}$ calcd for $\mathrm{C}_{52} \mathrm{H}_{67} \mathrm{~N}_{12} \mathrm{O}_{20}+\mathrm{H}^{+}[\mathrm{M}+\mathrm{H}]^{+}$1179.4595, found 1179.4610 .

4.1.3.1. $N, N^{\prime}, N^{\prime \prime}$-tri-[2-O-(2,3,4,6-tetra-O-acetyl- $\beta$-D-galactopyranosyl)-ethyl-1,2,3-triazol-4-ylmethylamide)-benzene-1,3,5tricarboxamide (12c). Prepared from 11 and 2-O-(2,3,4,6-tetra-Oacetyl- $\beta$-D-galactopyranosyl)ethyl azide [42] according to Method A: Off-white amorphous solid (69 mg, 50\%). [ $\alpha]_{\mathrm{D}}^{23}-5.8$ (c 0.7, DCM). ${ }^{1} \mathrm{H}$ NMR $\left(500 \mathrm{MHz} \mathrm{CDCl}_{3}\right): \delta 8.22\left(\mathrm{~s}, 3 \mathrm{H}, \mathrm{NHCH}_{2}\right.$-triaz), $8.16(\mathrm{~s}, 3 \mathrm{H}$, triaz-H), $7.67(\mathrm{~s}, 3 \mathrm{H}, \mathrm{Ar}-\mathrm{H}), 5.34(\mathrm{~d}, J=3.2 \mathrm{~Hz}, 3 \mathrm{H}, \mathrm{H}-4), 5.12$ (dd, $J=10.4,8.0 \mathrm{~Hz}, 3 \mathrm{H}, \mathrm{H}-2), 4.98(\mathrm{dd}, J=10.5,3.4 \mathrm{~Hz}, 3 \mathrm{H}, \mathrm{H}-3$ ), 4.79-4.50 (m, $12 \mathrm{H}, \mathrm{CH}_{2}$-triaz and $\left.\mathrm{CH}_{2} \mathrm{CH}_{2} \mathrm{O}\right), 4.47(\mathrm{~d}, J=7.9 \mathrm{~Hz}, 3 \mathrm{H}$, $\mathrm{H}-1$ ), 4.28-4.18 (m, 3H, CHO-Gal), 4.09 (dd, $J=11.3,6.6 \mathrm{~Hz}, 6 \mathrm{H}, \mathrm{H}-6$ and $\mathrm{H}_{-6}$ '), 4.00-3.86 ( $\mathrm{m}, 6 \mathrm{H}, \mathrm{CHO}-\mathrm{Gal}$ and $\left.\mathrm{H}-5\right), 2.11$ (s, 9H, OAc), $2.00(\mathrm{~s}, 9 \mathrm{H}, \mathrm{OAc}), 1.93$ (s, 18H, OAc x 2). ${ }^{13} \mathrm{C} \mathrm{NMR}\left(125 \mathrm{MHz}, \mathrm{CDCl}_{3}\right)$ : $\delta 170.4$ (CO of OAc), 170.1 (CO of OAc), 170.0 (CO of OAc), 169.7 (CO of OAc), 165.9 ( $\mathrm{CONHCH}_{2}$-triaz), 144.7 (C-triaz), $134.6(\mathrm{Ar}-\mathrm{C}), 128.5$ (CH-triaz), $123.6(\mathrm{Ar}-\mathrm{CH}), 100.9$ (C-1), 70.6 (C-5), 68.6 (C-3), 67.5 (C-2), $67.0\left(\mathrm{CH}_{2} \mathrm{CH}_{2} \mathrm{O}-\mathrm{Gal}\right), 61.2(\mathrm{C}-4), 50.1$ (C-6), $35.5\left(\mathrm{CH}_{2}\right.$-triaz), $20.7\left(\mathrm{CH}_{3}\right.$ of $\left.\mathrm{OAc}\right), 20.6\left(\mathrm{CH}_{3}\right.$ of $\left.\mathrm{OAc}\right), 20.6\left(\mathrm{CH}_{3}\right.$ of $\left.\mathrm{OAc}\right), 20.5\left(\mathrm{CH}_{3}\right.$ of OAc). IR (film on $\mathrm{NaCl}): 3391,2939,1748,1661,1537 \mathrm{~cm}^{-1}$. HRMS $(\mathrm{ESI}+): \mathrm{m} / z$ calcd for $\mathrm{C}_{66} \mathrm{H}_{84} \mathrm{~N}_{12} \mathrm{O}_{33}+\mathrm{H}^{+}[\mathrm{M}+\mathrm{H}]^{+} 1573.5342$, found 1574.5422 .

4.1.3.1. $N, N^{\prime}, N^{\prime \prime}$-tri-( $\beta$-D-galactopyranosyl-1,2,3-triazol-4ylmethylamide)-benzene-1,3,5-tricarboxamide (3a). Prepared from $N, N^{\prime}, N^{\prime \prime}$-tri-(2,3,4,6-tetra-O-acetyl- $\beta$-D-galactopyranosyl-1,2,3triazol-4-ylmethylamide)-benzene-1,3,5-tricarboxamide

(12a) [47]. Yellow amorphous solid (63 mg, 89\%). [ $\alpha]_{\mathrm{D}}^{23}+11.1\left(\mathrm{c} 0.6, \mathrm{H}_{2} \mathrm{O}\right)$. ${ }^{1} \mathrm{H}$ NMR $\left(500 \mathrm{MHz}, \mathrm{D}_{2} \mathrm{O}\right): \delta 8.24(\mathrm{~s}, 3 \mathrm{H}$, triaz-H), $8.19(\mathrm{~s}, 3 \mathrm{H}, \mathrm{Ar}-\mathrm{H})$, $5.65(\mathrm{~d}, J=9.2 \mathrm{~Hz}, 3 \mathrm{H}, \mathrm{H}-1), 4.64\left(\mathrm{~s}, 6 \mathrm{H}, \mathrm{CH}_{2}\right.$-triaz), $4.19(\mathrm{t}, J=9.5 \mathrm{~Hz}$, $3 \mathrm{H}, \mathrm{H}-2), 4.06$ (d, J=3.2 Hz, 3H, H-4), 3.96 (t, J=6.1 Hz, 3H, H-5), $3.85(\mathrm{dd}, J=9.8,3.3 \mathrm{~Hz}, 3 \mathrm{H}, \mathrm{H}-3), 3.74(\mathrm{~d}, J=6.0 \mathrm{~Hz}, 6 \mathrm{H}, \mathrm{H}-6$ and $\mathrm{H}-$ 6 '). ${ }^{13} \mathrm{C}$ NMR $\left(125 \mathrm{MHz}, \mathrm{D}_{2} \mathrm{O}\right): \delta 168.1\left(\mathrm{CONHCH}_{2}\right.$-triaz), $144.8(\mathrm{C}-$ triaz), $134.3(\mathrm{Ar}-\mathrm{C}), 129.2(\mathrm{Ar}-\mathrm{CH}), 123.2(\mathrm{CH}-$ triaz$), 88.2(\mathrm{C}-1), 78.3$ (C-5), 73.0 (C-3), 69.8 (C-2), 68.6 (C-4), 60.9 (C-6), 35.1 ( $\mathrm{CH}_{2}$-triaz). IR (KBr): $3402,1658,1539, \mathrm{~cm}^{-1}$. HRMS (ESI+): $\mathrm{m} / \mathrm{z}$ calcd for $\mathrm{C}_{36} \mathrm{H}_{48} \mathrm{~N}_{12} \mathrm{O}_{18}+\mathrm{H}^{+}[\mathrm{M}+\mathrm{H}]^{+}$937.3288, found 937.3201.

4.1.3.1. $N, N^{\prime}, N^{\prime \prime}$-tri-( $\beta$-L-fucopyranosyl-1,2,3-triazol-4ylmethylamide)-benzene-1,3,5-tricarboxamide (3b). Yellow amorphous solid (53 mg, 88\%). [ $\alpha]_{D}^{21.5}-5.6$ (c $\left.0.5, \mathrm{H}_{2} \mathrm{O}\right) .{ }^{1} \mathrm{H}$ NMR $\left(500 \mathrm{MHz}, \mathrm{D}_{2} \mathrm{O}\right): \delta 8.26(\mathrm{~s}, 3 \mathrm{H}, \mathrm{Ar}-H), 8.25(\mathrm{~s}, 3 \mathrm{H}$, triaz-H), $5.66(\mathrm{~d}$, $J=9.2 \mathrm{~Hz}, 3 \mathrm{H}, \mathrm{H}-1), 4.70$ (s, $6 \mathrm{H}, \mathrm{CH}_{2}$-triaz), 4.19 (t, $J=9.4 \mathrm{~Hz}, 3 \mathrm{H}, \mathrm{H}-$ 2), 4.10-4.06 (m, 3H, H-5), 3.91 (dd, $J=3.4,0.8 \mathrm{~Hz}, 3 \mathrm{H}, \mathrm{H}-4), 3.88$ 
(dd, $J=9.7,3.4 \mathrm{~Hz}, 3 \mathrm{H}, \mathrm{H}-3), 1.28-1.26\left(\mathrm{~m}, 9 \mathrm{H}, \mathrm{C} 6-\mathrm{H}_{3}\right) .{ }^{13} \mathrm{C} \mathrm{NMR}$ (125 MHz, $\mathrm{D}_{2} \mathrm{O}$ ): $\delta 168.3$ ( $\mathrm{CONHCH}_{2}$-triaz), 144.9 (C-triaz), 134.3 $(\mathrm{Ar}-\mathrm{C}), 129.2(\mathrm{Ar}-\mathrm{CH}), 123.0$ (CH-triaz), 88.1 (C-1), 74.4 (C-5), 73.1 (C-3), 71.2 (C-4), 69.5 (C-2), $35.1\left(\mathrm{CH}_{2}\right.$-triaz), 15.6 (C-6). IR ( $\left.\mathrm{KBr}\right)$ : 3381, 1659, $1536 \mathrm{~cm}^{-1}$. HRMS (ESI+): $\mathrm{m} / \mathrm{z}$ calcd for $\mathrm{C}_{38} \mathrm{H}_{54} \mathrm{~N}_{12} \mathrm{O}_{15}+\mathrm{Na}^{+}[\mathrm{M}+\mathrm{Na}]^{+}$941.3729, found 941.3709 .

4.1.3.1. $N, N^{\prime}, N^{\prime \prime}$-tri-[2-O-( $\beta$-D-galactopyranosyl)-ethyl-1,2,3-triazol4-ylmethylamide)-benzene-1,3,5-tricarboxamide (3c). Pale yellow amorphous solid $(34 \mathrm{mg}, 83 \%)$. $[\alpha]_{\mathrm{D}}^{20}+5.9$ (c $\left.0.7, \mathrm{H}_{2} \mathrm{O}\right) .{ }^{1} \mathrm{H}$ NMR $\left(500 \mathrm{MHz}, \mathrm{D}_{2} \mathrm{O}\right): \delta 8.31$ (bs, $3 \mathrm{H}$, triaz-H), $8.18(\mathrm{~s}, 2 \mathrm{H}, \mathrm{Ar}-\mathrm{H}), 8.12(\mathrm{~s}$, $1 \mathrm{H}, \mathrm{Ar}-\mathrm{H}$ ), 4.71 (bs, $6 \mathrm{H}, \mathrm{CH}_{2}$-triaz), 4.58-4.56 (m, 3H, $\left.\mathrm{CHCH}_{2}\right)$, 4.37-4.26 $\left(\mathrm{m}, 6 \mathrm{H}, \mathrm{H}-1\right.$ and $\left.\mathrm{CHCH}_{2}\right), 4.12\left(\mathrm{~m}, 3 \mathrm{H}, \mathrm{CHCH}_{2}\right), 3.96-3.90$ $\left(\mathrm{m}, 3 \mathrm{H}, \mathrm{CHCH}_{2}\right), 3.87(\mathrm{~d}, \mathrm{~J}=3.3 \mathrm{~Hz}, 3 \mathrm{H}, \mathrm{H}-4), 3.76-3.68(\mathrm{~m}, 6 \mathrm{H}, \mathrm{H}-6$ and $\left.\mathrm{H}-6^{\prime}\right), 3.65-3.60(\mathrm{~m}, 3 \mathrm{H}, \mathrm{H}-5), 3.59-3.56(\mathrm{~m}, 3 \mathrm{H}, \mathrm{H}-3)$, 3.49-3.42 (m, 3H, H-2). ${ }^{13} \mathrm{C}$ NMR (125 MHz, $\left.\mathrm{D}_{2} \mathrm{O}\right): \delta 167.8$ ( $\mathrm{CONHCH}_{2}$-triaz), 143.8 (C-triaz), $134.4(\mathrm{Ar}-\mathrm{C}), 129.3$ (CH-triaz), $125.3(\mathrm{Ar}-\mathrm{CH}), 124.9(\mathrm{Ar}-\mathrm{CH}) 103.0(\mathrm{C}-1), 96.5,75.1(\mathrm{C}-5), 72.8(\mathrm{H}-$ 3), 72.6, 71.9, 70.6 (C-2), $68.6(\mathrm{C}-4), 67.8\left(\mathrm{CH}_{2} \mathrm{CH}_{2}\right), 61.0,60.9$ (C-6), 60.0, 53.1, $51.0\left(\mathrm{CH}_{2} \mathrm{CH}_{2}\right), 34.8\left(\mathrm{CH}_{2}\right.$-triaz). IR (ATR): 3267, 2931, $1655,1537 \mathrm{~cm}^{-1}$. HRMS (ESI+): $m / z$ calcd for $\mathrm{C}_{42} \mathrm{H}_{60} \mathrm{~N}_{12} \mathrm{O}_{21}+\mathrm{H}^{+}$ $[\mathrm{M}+\mathrm{H}]^{+}$1069.4074, found 1069.4091.

4.1.3.1. $N$-(2,3,4,6-tetra-O-acetyl- $\beta$-D-mannopyranosy) $l-1,2,3$ triazol-4-ylme thylamide- $N^{\prime}$-prop-2-yn-1-yl-N" - propyl-5aminobenzene-1,3-dicarboxamide (13). 6 (435 $\mathrm{mg}, 1.40 \mathrm{mmol})$ and 2,3,4,6-tetra-O-acetyl-1- $\alpha$-azido-mannoside [43] (131 mg, $0.349 \mathrm{mmol}$ ) were reacted according to Method B: yellow amorphous solid (91 mg, 34\%). $\mathrm{R}_{f}=0.45$ (DCM:MeOH 9:1). $[\alpha]_{\mathrm{D}}^{23}+12.1$ (c $0.9, \mathrm{MeOH}) .{ }^{1} \mathrm{H}$ NMR $\left(500 \mathrm{MHz}, \mathrm{CDCl}_{3}\right): \delta 9.15\left(\mathrm{~s}, 1 \mathrm{H}, \mathrm{NHCOC}_{2} \mathrm{H}_{5}\right.$ ), $8.13\left(\mathrm{~s}, 1 \mathrm{H}, \mathrm{NHCH}_{2}\right.$ triaz), 8.07 (s, $\left.1 \mathrm{H}, \mathrm{Ar}-\mathrm{H}\right), 8.02(\mathrm{~s}, 1 \mathrm{H}, \mathrm{Ar}-\mathrm{H}), 7.87$ (s, $1 \mathrm{H}$, triaz-H), $7.78(\mathrm{~s}, 1 \mathrm{H}, \mathrm{Ar}-\mathrm{H}), 7.68\left(\mathrm{~s}, 1 \mathrm{H}, \mathrm{NHCH}_{2}\right.$-triaz), $6.04(\mathrm{~s}$, $1 \mathrm{H}, \mathrm{H}-1), 5.91-5.84(\mathrm{~m}, 2 \mathrm{H}, \mathrm{H}-2$ and $\mathrm{H}-3), 5.40(\mathrm{t}, J=9.5 \mathrm{~Hz}, 1 \mathrm{H}, \mathrm{H}-$ 4), 4.73-4.58 (m, $2 \mathrm{H}, \mathrm{CH}_{2}$-triaz), 4.27 (dd, $\left.J=12.5,4.7 \mathrm{~Hz}, 1 \mathrm{H}, \mathrm{H}-6\right)$, 4.13 (s, 2H, $\mathrm{CH}_{2} \mathrm{CCH}$ ), 4.03 (d, $J=10.6 \mathrm{~Hz}, 1 \mathrm{H}, \mathrm{H}-6$ ), $3.96-3.87$ (m, $1 \mathrm{H}, \mathrm{H}-5), 2.36$ (q, $\left.J=7.4 \mathrm{~Hz}, 2 \mathrm{H}, \mathrm{CH}_{2} \mathrm{CH}_{3}\right), 2.19$ (d, $J=7.6 \mathrm{~Hz}, 1 \mathrm{H}$, $\mathrm{CH}_{2} \mathrm{CCH}$ ), 2.17 (s, 3H, OAc), 2.05 (s, 3H, OAc), 2.02 (s, 3H, OAc), 2.00 $(\mathrm{s}, 3 \mathrm{H}, \mathrm{OAc}), 1.11\left(\mathrm{t}, J=7.5 \mathrm{~Hz}, 3 \mathrm{H}, \mathrm{CH}_{2} \mathrm{CH}_{3}\right) .{ }^{13} \mathrm{C}$ NMR $(125 \mathrm{MHz}$, $\mathrm{CDCl}_{3}$ ): $\delta 173.5\left(\mathrm{COC}_{2} \mathrm{H}_{5}\right), 170.6$ (CO of OAc), 170.0 (CO of OAc), 169.7 (CO of OAc), 169.6 (CO of OAc), $166.8\left(\mathrm{CONHCH}_{2}\right.$-triaz), 166.7 ( $\mathrm{CONHCH}_{2}$-triaz), 145.4 (C-triaz), 139.3 ( $\left.\mathrm{Ar}-\mathrm{C}\right), 134.6(\mathrm{Ar}-\mathrm{C}), 123.4$ (CH-triaz), $121.4(\mathrm{Ar}-\mathrm{CH}$ x2), $120.7(\mathrm{Ar}-\mathrm{CH}), 84.0(\mathrm{C}-1), 79.7$ $\left(\mathrm{CH}_{2} \mathrm{CCH}\right), 71.9(\mathrm{C}-5), 69.3(\mathrm{C}-2 / \mathrm{C}-3), 68.3(\mathrm{C}-2 / \mathrm{C}-3), 65.6(\mathrm{C}-4), 61.7$ (C-6), 35.3 ( $\mathrm{CH}_{2}$-triaz), $30.3\left(\mathrm{CH}_{2} \mathrm{CCH}\right), 29.7\left(\mathrm{CH}_{2} \mathrm{CH}_{3}\right), 29.3$ $\left(\mathrm{CH}_{2} \mathrm{CCH}\right), 20.8\left(\mathrm{CH}_{3}\right.$ of $\left.\mathrm{OAc}\right), 20.7\left(\mathrm{CH}_{3}\right.$ of $\left.\mathrm{OAc}\right), 20.7\left(\mathrm{CH}_{3}\right.$ of $\left.\mathrm{OAc}\right)$, $20.6\left(\mathrm{CH}_{3}\right.$ of OAc), 9.4 $\left(\mathrm{CH}_{2} \mathrm{CH}_{3}\right)$. IR (film on $\left.\mathrm{NaCl}\right)$ : $3289,3082,2981$, $1751,1653,1598,1535 \mathrm{~cm}^{-1}$. HRMS (ESI +$): \mathrm{m} / z$ calcd for $\mathrm{C}_{29} \mathrm{H}_{39} \mathrm{~N}_{9} \mathrm{O}_{13}+\mathrm{Na}^{+}[\mathrm{M}+\mathrm{Na}]^{+} 744.2565$, found 744.2575.

4.1.3.1. $N$-(2,3,4,6-tetra-O-acetyl- $\beta$-D-galactopyranosyl)-1,2,3triazol-4-ylmethylamide- $N$ '-(2,3,4,6-tetra-O-acetyl- $\alpha$-D-mannopyranosyl)-1,2,3-triazol-4-ylmethylamide- $N^{\prime \prime}$-propyl-5-aminobenzene1,3-dicarboxamide (14). 13 (77 mg, $0.112 \mathrm{mmol}$ ) and 2,3,4,6-tetra$O$-acetyl- $\beta$-D-galactopyranosyl azide [34] (50 mg, $0.134 \mathrm{mmol}$ ) were reacted according to Method $B$ : yellow amorphous solid $(100 \mathrm{mg}$, 84\%). $\mathrm{R}_{f}=0.48$ (DCM:MeOH 9:1). [ $\left.\alpha\right]_{\mathrm{D}}^{21}+9.0$ (c 1, DCM). ${ }^{1} \mathrm{H}$ NMR $\left(500 \mathrm{MHz}, \mathrm{CDCl}_{3}\right): \delta 8.89(\mathrm{~s}, 1 \mathrm{H}, \mathrm{NH}), 8.20(\mathrm{~s}, 1 \mathrm{H}, \mathrm{NH}), 8.14(\mathrm{~s}, 2 \mathrm{H}$, triaz-H), $8.02(\mathrm{~m}, 3 \mathrm{H}, \mathrm{Ar}-\mathrm{H} \mathrm{x} 2$ and $\mathrm{NH}), 7.81(\mathrm{~s}, 1 \mathrm{H}, \mathrm{Ar}-\mathrm{H}), 6.22(\mathrm{~d}$, $J=1.8 \mathrm{~Hz}, 1 \mathrm{H}$, (H-1 Man)), $6.12(\mathrm{dd}, J=3.6,2.0 \mathrm{~Hz}, 1 \mathrm{H}, \mathrm{H}-2$ (Man)), 6.09-6.02 (m, 2H, H-3 (Man) and H-1 (Gal)), 5.75 (t, $J=9.7 \mathrm{~Hz}, 1 \mathrm{H}$, $\mathrm{H}-2$ (Gal)), 5.67 (dd, $J=3.3,0.7 \mathrm{~Hz}, 1 \mathrm{H}, \mathrm{H}-4$ (Gal)), 5.55 (dd, $J=12.5$, $6.8 \mathrm{~Hz}, 1 \mathrm{H}, \mathrm{H}-2$ (Gal)), 5.44-5.39 (m, 1H, H-3 (Gal)), 4.87-4.71 (m, $4 \mathrm{H}, \mathrm{CH}_{2}$-triaz x2), 4.47-4.39 (m, 2H, H-6 (Man) and H-5 (Gal)), 4.29 (dd, $J=11.5,6.5 \mathrm{~Hz}, 2 \mathrm{H}, \mathrm{H}-6$ and H-6' (Gal)), 4.22-4.15 (m, 1H, H-6' (Man)), 4.09 (ddd, $J=9.6,4.4,2.5 \mathrm{~Hz}, 1 \mathrm{H}, \mathrm{H}-5$ (Man)), 2.52 (q,
$\left.J=7.4 \mathrm{~Hz}, 2 \mathrm{H}, \mathrm{CH}_{2} \mathrm{CH}_{3}\right), 2.32(\mathrm{~d}, J=4.0 \mathrm{~Hz}, 6 \mathrm{H}, \mathrm{OAc} \times 2), 2.20(\mathrm{~s}, 3 \mathrm{H}$, OAc), 2.16 (s, 3H, OAc), 2.14 (s, 3H, OAc), 2.12 (s, 6H, OAc x2), 1.96 (s, $3 \mathrm{H}, \mathrm{OAc}), 1.28\left(\mathrm{t}, J=7.5 \mathrm{~Hz}, 3 \mathrm{H}, \mathrm{CH}_{2} \mathrm{CH}_{3}\right) .{ }^{13} \mathrm{C} \mathrm{NMR}\left(125 \mathrm{MHz}, \mathrm{CDCl}_{3}\right)$ : $\delta 173.4\left(\mathrm{COC}_{2} \mathrm{H}_{5}\right), 170.8$ (CO of OAc), 170.5 (CO of OAc), 170.3 (CO of OAc), 170.0 (CO of OAc), 170.0 (CO of OAc), 169.8 (CO of OAc), 169.4 (CO of OAc), 166.9 ( $\mathrm{CONHCH}_{2}$-triaz), $166.8\left(\mathrm{CONHCH}_{2}\right.$-triaz), 145.8 (C-triaz), 145.7 (C-triaz), 139.2 ( $\mathrm{Ar}-\mathrm{C}), 134.9(\mathrm{Ar}-\mathrm{C}), 134.8(\mathrm{Ar}-\mathrm{C})$, 123.6 ( $\mathrm{Ar}-\mathrm{CH}), 121.6$ (CH-triaz), $120.7(\mathrm{Ar}-\mathrm{CH}), 86.3$ (C-1 Gal), 84.2 (C-1 Man), 74.1 (C-5 Gal), 72.0 (C-5 Man), 71.0 (C-3 Gal), 69.4 (C-3 Man), 68.5 (C-2 Man), 68.2 (C-2 Gal), 67.1 (C-4 Gal), 65.8 (C-4 Man), 61.9 (C-6 Man), 61.3 (C-6 Gal), $35.6\left(\mathrm{CH}_{2}\right.$-triaz), $35.4\left(\mathrm{CH}_{2}\right.$-triaz), $30.5\left(\mathrm{CH}_{2} \mathrm{CH}_{3}\right), 20.9\left(\mathrm{CH}_{3}\right.$ of $\left.\mathrm{OAc}\right), 20.8\left(\mathrm{CH}_{3}\right.$ of $\left.\mathrm{OAc}\right), 20.8\left(\mathrm{CH}_{3}\right.$ of OAc), $20.8\left(\mathrm{CH}_{3}\right.$ of $\left.\mathrm{OAc}\right), 20.7\left(\mathrm{CH}_{3}\right.$ of $\left.\mathrm{OAc}\right), 20.4\left(\mathrm{CH}_{3}\right.$ of $\left.\mathrm{OAc}\right), 9.6$ $\left(\mathrm{CH}_{2} \mathrm{CH}_{3}\right)$. IR (film on $\left.\mathrm{NaCl}\right)$ : 3311, 3147, 3082, 2981, 1750, 1657, 1599, $1548 \mathrm{~cm}^{-1}$. HRMS (ESI + ): $\mathrm{m} / \mathrm{z}$ calcd for $\mathrm{C}_{45} \mathrm{H}_{56} \mathrm{~N}_{9} \mathrm{O}_{21}+\mathrm{H}^{+}$ $\left[\mathrm{M}+\mathrm{H}^{+}\right]$: 1058.3591 , found 1058.3607 .

4.1.3.1. $N-\beta$-D-galactopyranosyl-1,2,3-triazol-4-ylmethylamide- $N^{\prime}-\alpha-$ D-mannopyranosyl-1,2,3-triazol-4-ylmethylamide)- $N^{\prime \prime}$-propyl-5aminobenzene-1,3-dicarboxamide (4). Pale yellow amorphous solid (84 mg, 89\%). $[\alpha]_{\mathrm{D}}^{26}+13.1$ (c $\left.0.8, \mathrm{H}_{2} \mathrm{O}\right) .{ }^{1} \mathrm{H}$ NMR $\left(500 \mathrm{MHz}, \mathrm{D}_{2} \mathrm{O}\right)$ : $\delta 8.23(\mathrm{~s}, 1 \mathrm{H}$, triaz-H), $8.14(\mathrm{~s}, 1 \mathrm{H}$, triaz-H), $7.85(\mathrm{~s}, 1 \mathrm{H}, \mathrm{Ar}-\mathrm{H}), 7.83(\mathrm{~s}$, $1 \mathrm{H}, \mathrm{Ar}-\mathrm{H}), 7.77(\mathrm{~s}, 1 \mathrm{H}, \mathrm{Ar}-\mathrm{H}), 6.07(\mathrm{~d}, J=2.2 \mathrm{~Hz}, 1 \mathrm{H}, \mathrm{H}-1 \mathrm{Man}), 5.65$ (d, $J=9.2 \mathrm{~Hz}, 1 \mathrm{H}, \mathrm{H}-1 \mathrm{Gal}$ ), 4.72 (dd, $J=6.4,3.6 \mathrm{~Hz}, 1 \mathrm{H}, \mathrm{H}-2 \mathrm{Man}$ ), 4.62 (s, $4 \mathrm{H}, \mathrm{CH}_{2}$-triaz x2), 4.18 (t, $J=9.5 \mathrm{~Hz}, 1 \mathrm{H}, \mathrm{H}-2 \mathrm{Gal}$ ), 4.10 (dd, $J=9.0,3.4 \mathrm{~Hz}, 1 \mathrm{H}, \mathrm{H}-3 \mathrm{Man}), 4.06(\mathrm{~d}, J=3.2 \mathrm{~Hz}, 1 \mathrm{H}, \mathrm{H}-4 \mathrm{Gal}), 3.96(\mathrm{t}$, $J=6.0 \mathrm{~Hz}, 1 \mathrm{H}, \mathrm{H}-5 \mathrm{Gal}), 3.85$ (dd, $J=9.8,3.2 \mathrm{~Hz}, 1 \mathrm{H}, \mathrm{H}-3 \mathrm{Gal}$ ), 3.81-3.70 ( $\mathrm{m}, 5 \mathrm{H}, \mathrm{H}-4$ Man, H-6, H-6' Gal, H-6, H-6' Man), 3.30 (ddd, $J=8.9,5.1,1.7 \mathrm{~Hz}, 1 \mathrm{H}, \mathrm{H}-5 \mathrm{Man}$ ), 2.35 (q, $J=7.6 \mathrm{~Hz}, 2 \mathrm{H}$, $\left.\mathrm{CH}_{2} \mathrm{CH}_{3}\right), 1.10\left(\mathrm{t}, J=7.6 \mathrm{~Hz}, 3 \mathrm{H}, \mathrm{CH}_{2} \mathrm{CH}_{3}\right) .{ }^{13} \mathrm{C}$ NMR $\left(125 \mathrm{MHz}, \mathrm{D}_{2} \mathrm{O}\right)$ : $\delta 176.3\left(\mathrm{COC}_{2} \mathrm{H}_{5}\right), 168.4\left(\mathrm{CONHCH}_{2}\right.$-triaz), 144.7 (C-triaz), 138.2 (Ar-C), 134.2 ( $\mathrm{Ar}-\mathrm{C}), 123.8$ (CH-triaz), 123.1 (CH-triaz), 122.3 $(\mathrm{Ar}-\mathrm{CH}), 121.7(\mathrm{Ar}-\mathrm{CH}), 88.2$ (C-1 Gal), 86.8 (C-1 Man), 78.3 (C-5 Gal), 76.2 (C-2 Man), 72.9 (C-3 Gal), 70.5 (C-3 Man), 69.8 (C-2 Gal), 68.6 (C-4 Gal), 68.3 (C-2 Man), 66.6 (C-4 Man), 60.9 (C-6 Gal), 60.5 (C-6 Man), $35.0\left(\mathrm{CH}_{2}\right.$-triaz), $34.9\left(\mathrm{CH}_{2}\right.$-triaz $), 29.8\left(\mathrm{CH}_{2} \mathrm{CH}_{3}\right), 9.1$ $\left(\mathrm{CH}_{2} \mathrm{CH}_{3}\right.$ ). IR (ATR): 3259, 2922, 2597, 1648, 1600, $1536 \mathrm{~cm}^{-1}$. HRMS $(\mathrm{ESI}+): \mathrm{m} / z$ calcd for $\mathrm{C}_{29} \mathrm{H}_{39} \mathrm{~N}_{9} \mathrm{O}_{13}+\mathrm{Na}^{+}[\mathrm{M}+\mathrm{Na}]+744.2565$, found 744.2575.

4.1.3.1. $N, N^{\prime}$-di-(2,3,4,6-tetra-O-acetyl- $\beta$-D-galactopyranosyl)- $N^{\prime \prime}-$ propyl-5-aminobenzene-1,3-dicarboxamide (15).

5-Propionamidoisophthalic acid $(0.133 \mathrm{~g}, 5.61 \mathrm{mmol})$ and TBTU $(0.396 \mathrm{~g}, 1.23 \mathrm{mmol})$ were dissolved in DMF $(10 \mathrm{~mL})$ under $\mathrm{N}_{2} . \mathrm{NEt}_{3}$ $(0.312 \mathrm{~mL}, 2.24 \mathrm{mmol})$ was added and the mixture was allowed to stir for 15 min. 2,3,4,6-tetra- $O$-acetyl- $\beta$-D-galactopyranosylamine [48] (0.487 g, $1.40 \mathrm{mmol})$ was dissolved in DMF ( $5 \mathrm{~mL}$ ) and was added to the reaction mixture. The solution was stirred for $24 \mathrm{~h}$. The crude mixture was dissolved in DCM $(30 \mathrm{Ml})$, washed with $0.5 \mathrm{M}$ $\mathrm{HCl}(30 \mathrm{~mL})$, sat. $\mathrm{NaHCO}_{3}(30 \mathrm{~mL})$ and brine $(30 \mathrm{~mL})$, and dried $\left(\mathrm{MgSO}_{4}\right)$. The mixture was filtered and the solvent was removed in vacuo to yield the crude product, which was purified by silica gel column chromatography (EtOAc) to give the pure product. Yellow amorphous solid (343 mg, 68\%). $\mathrm{R}_{f}=0.64$ (DCM:MeOH 9:1) $[\alpha]_{\mathrm{D}}^{25}$ -18.1 (c 1.1, DCM). ${ }^{1} \mathrm{H}$ NMR (500 MHz, $\left.\mathrm{CDCl}_{3}\right): \delta 8.41$ (s, 1H, NH), 8.23 $(\mathrm{s}, 2 \mathrm{H}, \mathrm{Ar}-\mathrm{H}), 7.86(\mathrm{~s}, 1 \mathrm{H}, \mathrm{Ar}-\mathrm{H}), 7.54(\mathrm{~d}, J=9.1 \mathrm{~Hz}, 2 \mathrm{H}, \mathrm{NH}), 5.59(\mathrm{t}$, $J=8.9 \mathrm{~Hz}, 2 \mathrm{H}, \mathrm{H}-1$ ), 5.47 (d, $J=1.5 \mathrm{~Hz}, 2 \mathrm{H}, \mathrm{H}-4), 5.31-5.29$ (m, 4H, $\mathrm{H}-2$ and $\mathrm{H}-3), 4.20(\mathrm{t}, J=6.6 \mathrm{~Hz}, 2 \mathrm{H}, \mathrm{H}-5), 4.16-4.05(\mathrm{~m}, 4 \mathrm{H}, \mathrm{H}-6$ and $\left.\mathrm{H}^{\prime}\right), 2.42(\mathrm{q}, J=7.5 \mathrm{~Hz}, 2 \mathrm{H}), 2.17\left(\mathrm{~s}, 6 \mathrm{H} \mathrm{CH}_{3}\right.$ of OAc), $2.01(\mathrm{~s}, 6 \mathrm{H}$, $\mathrm{CH}_{3}$ of $\left.\mathrm{OAc}\right), 1.99$ (s, $6 \mathrm{H}, \mathrm{CH}_{3}$ of $\left.\mathrm{OAc}\right), 1.97$ (s, $6 \mathrm{H}, \mathrm{CH}_{3}$ of $\left.\mathrm{OAc}\right) .{ }^{13} \mathrm{C}$ NMR (125 MHz, $\left.\mathrm{CDCl}_{3}\right): \delta 172.8\left(\mathrm{COC}_{2} \mathrm{H}_{5}\right), 171.3$ (CO of OAc), 170.5 (CO of OAc), 170.2 (CO of OAc), 170.1 (CO of OAc), 166.2 (CONH-Gal), 139.7 ( $\mathrm{Ar}-\mathrm{C}), 134.3(\mathrm{Ar}-\mathrm{C}), 121.9(\mathrm{Ar}-\mathrm{CH}), 120.7(\mathrm{Ar}-\mathrm{CH}), 79.0(\mathrm{C}-$ 1), 72.4 (C-5), 71.1 (C-2/3), 68.6 (C-2/3), 67.4 (C-4), 61.3 (C-6), 30.5 $\left(\mathrm{CH}_{2} \mathrm{CH}_{3}\right), 20.8\left(\mathrm{CH}_{3}\right.$ of $\left.\mathrm{OAc}\right), 20.7\left(\mathrm{CH}_{3}\right.$ of $\left.\mathrm{OAc}\right), 20.7\left(\mathrm{CH}_{3}\right.$ of $\left.\mathrm{OAc}\right)$, 
20.6 ( $\mathrm{CH}_{3}$ of $\mathrm{OAc}$ ), $9.4\left(\mathrm{CH}_{2} \mathrm{CH}_{3}\right)$. IR (film on $\mathrm{NaCl}$ ): 3338, 1750, 1602 , $1535, \mathrm{~cm}^{-1}$. HRMS (ESI +$): m / z$ calcd for $\mathrm{C}_{39} \mathrm{H}_{50} \mathrm{~N}_{3} \mathrm{O}_{21}+\mathrm{H}^{+}[\mathrm{M}+\mathrm{H}]^{+}$ 896.2931, found 896.2956.

4.1.3.1. $N, N^{\prime}$-di-( $\beta$-D-galactopyranosyl)- $N^{\prime \prime}$-propyl-5-aminobenzene1,3-dicarboxamide (5). White amorphous solid (26 mg, 96\%). $[\alpha]_{\mathrm{D}}^{20}+10.0(\mathrm{c} 1, \mathrm{MeOH}) .{ }^{1} \mathrm{H}$ NMR $\left(500 \mathrm{MHz}, \mathrm{D}_{2} \mathrm{O}\right): \delta 8.04(\mathrm{~d}$, $J=1.4 \mathrm{~Hz}, 2 \mathrm{H}, \mathrm{Ar}-\mathrm{H}$ ), $8.03(\mathrm{~d}, J=1.5 \mathrm{~Hz}, 1 \mathrm{H}, \mathrm{Ar}-\mathrm{H}), 5.10$ (d, $J=8.4 \mathrm{~Hz}, 2 \mathrm{H}, \mathrm{H}-1), 3.97$ (d, $J=3.0 \mathrm{~Hz}, 2 \mathrm{H}, \mathrm{H}-4), 3.82(\mathrm{t}, J=6.2 \mathrm{~Hz}$, $2 \mathrm{H}, \mathrm{H}-5$ ), 3.79-3.67 ( $\left.\mathrm{m}, 8 \mathrm{H}, \mathrm{H}-2, \mathrm{H}-3, \mathrm{H}-6, \mathrm{H}-6{ }^{\prime}\right), 2.47-2.37(\mathrm{~m}, 2 \mathrm{H}$, $\left.\mathrm{CH}_{2} \mathrm{CH}_{3}\right), 1.19-1.11\left(\mathrm{~m}, 3 \mathrm{H}, \mathrm{CH}_{2} \mathrm{CH}_{3}\right) .{ }^{13} \mathrm{C} \mathrm{NMR}\left(126 \mathrm{MHz}, \mathrm{D}_{2} \mathrm{O}\right)$

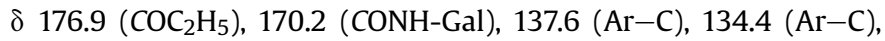
124.1 ( $\mathrm{Ar}-\mathrm{CH}), 123.0(\mathrm{Ar}-\mathrm{CH}), 80.5(\mathrm{C}-1), 77.0(\mathrm{C}-5), 73.5(\mathrm{C}-3), 69.3$ (C-2), 68.7 (C-4), 61.0 (C-6), $29.9\left(\mathrm{CH}_{2} \mathrm{CH}_{3}\right) 9.2\left(\mathrm{CH}_{2} \mathrm{CH}_{3}\right)$. HRMS (ESI+): $m / z$ calcd for $\mathrm{C}_{23} \mathrm{H}_{34} \mathrm{~N}_{3} \mathrm{O}_{13}+\mathrm{H}^{+}[\mathrm{M}+\mathrm{H}]^{+} 560.2086$, found 560.2072.Biology

\subsubsection{Sample Preparation}

All glycoconjugates (with exception of monovalent fucosyl derivative, compound $\mathbf{1 b}$ ) were dissolved in water at the required concentration $(10 \mathrm{mg} / \mathrm{mL}$ ) and dilutions from these stock solutions were performed as appropriate. Compound 1b was dissolved in DMSO and diluted with water to the required concentration (10 $\mathrm{mg} / \mathrm{mL}$ ), ensuring that the final DMSO content was below $10 \%$. Dilutions from this stock solution were performed as appropriate.

\subsubsection{Fungal Strain}

C. albicans was maintained on sabouraud dextrose agar and cultures were grow to the stationary phase $\left(1-2 \times 10^{8} / \mathrm{ml}\right)$ overnight in YEPD broth $(1 \%(\mathrm{w} / \mathrm{v})$ yeast extract, $2 \%(\mathrm{w} / \mathrm{v})$ bacteriological peptone, $2 \%(\mathrm{w} / \mathrm{v})$ glucose $)$ at $30^{\circ} \mathrm{C}$ and $200 \mathrm{rpm}$. Stationary phase yeast cells were harvested, washed with PBS and resuspended at a density of $1 \times 10^{8} / \mathrm{mL}$ in PBS.

4.1.5.1Buccal epithelial cells

Buccal epithelial cells (BECs) were harvested from healthy volunteers by gently scraping the inside of the cheek with a sterile tongue depressor. Cells were washed in PBS and resuspended at a density of $5 \times 10^{5} / \mathrm{ml}$.

\subsubsection{Adherence assays}

Yeast cells were mixed with BECs in a ratio of 50:1 in a final volume of $2 \mathrm{~mL}$ and incubated at $30^{\circ} \mathrm{C}$ and $200 \mathrm{rpm}$ for $90 \mathrm{~min}$. The $\mathrm{BEC} /$ yeast cell mixture was harvested by passing through a polycarbonate membrane containing $30 \mu \mathrm{m}$ pores which trapped the BECs but allowed unattached yeast cells to pass through. This was washed $\times 2$ with $10 \mathrm{~mL}$ PBS and cells remaining on the membrane were collected and placed on glass slides which were left to air dry overnight. The cells were heat fixed and stained using $0.5 \%(\mathrm{w} / \mathrm{v})$ crystal violet, rinsed using cold water to remove any surplus stain and left to air dry for $30 \mathrm{~min}$. The number of $C$. albicans cells adhering to a sample of 200 BECs per treatment was assessed microscopically. In the exclusion assay the yeast cells were incubated for $90 \mathrm{~min}$ in the presence of each compound $(10 \mathrm{mg} / \mathrm{mL})$. After this time the cells were harvested and washed twice with PBS before being resuspended in $1 \mathrm{~mL}$ PBS before being mixed with BECs (as described). In the competition assay format yeast cells, BECs and compound $(10,1$ or $0.1 \mathrm{mg} / \mathrm{mL})$ were co-incubated for 90 min prior to harvesting. In the displacment assay adherence was allowed to occur by mixing the yeast cells and BECs together. BECs and adherent yeast cells were harvested and re-incubated with the compound $(0.1 \mathrm{mg} / \mathrm{mL})$ for a further $90 \mathrm{~min}$ after which time the level of adherence was measured.

\subsubsection{Statistics}

All experiments were performed on three independent occasions. In each assay the number of yeast cells adhering to 200 randomly chosen BECs was determined. Results are mean \pm SEM.

\subsection{Fluorescence imaging}

An Olympus Fluoview FV1000 confocal microscope was employed to visualise the binding of the fluorescently labelled galactoside 8 to the $C$. albicans cell surface. A wavelength of $488 \mathrm{~nm}$ laser was used for excitation and emission was detected at $500-600 \mathrm{~nm}$.

\section{Associated content}

Electronic Supporting Information (ESI) is available free of charge via the Internet at http://pubs.acs.org. It includes detailed optimized experimental procedures for the synthetic materials and spectroscopic data.

\section{Funding sources}

We would like to acknowledge Maynooth University for the provision of the John and Pat Hume Scholarship to H. Martin and the Irish Research Council for the award of a Postgraduate Scholarship to Lorna Abbey.

\section{Acknowledgment}

The authors acknowledge the assistance of Dr. Ilona Dix for assistance with confocal microscopy.

\section{Appendix A. Supplementary data}

Supplementary data to this article can be found online at https://doi.org/10.1016/j.ejmech.2018.10.011.

$\begin{array}{ll}\text { Abbreviations } \\ \text { Asc } & \text { ascorbic } \\ \text { Triaz } & \text { triazolyl } \\ \text { YEPD } & \text { Yeast extract Peptone Dextrose }\end{array}$

\section{References}

[1] J. Pizarro-Cerdá, P. Cossart, Bacterial adhesion and entry into host cells, Cell 124 (2006) 715-727.

[2] E.C. Boyle, B.B. Finlay, Bacterial pathogenesis: exploiting cellular adherence, Curr. Opin. Cell Biol. 15 (2003) 633-639.

[3] K.A. Kline, S. Fälker, S. Dahlberg, S. Normark, B. Henriques-Normark, Bacterial adhesins in host-microbe interactions, Cell Host Microbe 5 (2009) 580-592.

[4] I. Ofek, D.L. Hasty, N. Sharon, Anti-adhesion therapy of bacterial diseases: prospects and problems, FEMS Immunol. Med. Microbiol. 38 (2003) 181-191.

[5] N.P. Pera, R.J. Pieters, Towards bacterial adhesion-based therapeutics and detection methods, MedChemComm 5 (2014) 1027-1035.

[6] S. Sattin, A. Bernardi, Glycoconjugates and glycomimetics as microbial antiadhesives, Trends Biotechnol. 34 (2016) 483-495.

[7] A.M. Boukerb, A. Rousset, N. Galanos, J.-B. Méar, M. Thépaut, T. Grandjean, E. Gillon, S. Cecioni, C. Abderrahmen, K. Faure, D. Redelberger, E. Kipnis, R. Dessein, S. Havet, B. Darblade, S.E. Matthews, S. de Bentzmann, B. Guéry, B. Cournoyer, A. Imberty, S. Vidal, Antiadhesive properties of glycoclusters against Pseudomonas aeruginosa lung infection, J. Med. Chem. 57 (2014) 10275-10289.

[8] D. Alvarez Dorta, A. Sivignon, T. Chalopin, T.I. Dumych, G. Roos, R.O. Bilyy, D. Deniaud, E.-M. Krammer, J. de Ruyck, M.F. Lensink, J. Bouckaert, N. Barnich, S.G. Gouin, The antiadhesive strategy in Crohn's Disease: orally active mannosides to decolonize pathogenic Escherichia coli from the gut, Chembiochem 17 (2016) 936-952.

[9] L. Mydock-McGrane, Z. Cusumano, Z. Han, J. Binkley, M. Kostakioti, T. Hannan, J.S. Pinkner, R. Klein, V. Kalas, J. Crowley, N.P. Rath, S.J. Hultgren, J.W. Janetka, Antivirulence C-mannosides as antibiotic-sparing, oral therapeutics for urinary tract infections, J. Med. Chem. 59 (2016) 9390-9408.

[10] X. Jiang, D. Abgottspon, S. Kleeb, S. Rabbani, M. Scharenberg, M. Wittwer, 
M. Haug, O. Schwardt, B. Ernst, Antiadhesion therapy for urinary tract infections- a balanced PK/PD profile proved to be key for success, J. Med. Chem. 55 (2012) 4700-4713.

[11] S. Cecioni, A. Imberty, S. Vidal, Glycomimetics versus multivalent glycoconjugates for the design of high affinity lectin ligands, Chem. Rev. 115 (2015) $525-561$.

[12] T.M. Arendorf, D.M. Walker, The prevalence and intra-oral distribution of Candida albicans in man, Arch. Oral Biol. 25 (1980) 1-10.

[13] J. Naglik, A. Albrecht, O. Bader, B. Hube, Candida albicans proteinases and host/ pathogen interactions, Cell Microbiol. 6 (2004) 915-926.

[14] L.R. Martinez, B.C. Fries, Fungal biofilms: relevance in the setting of human disease, Curr. Fungal Infect. Rep. 4 (2010) 266-275.

[15] A.M. Krachler, K. Orth, Targeting the bacteria-host interface: strategies in antiadhesion therapy, Virulence 4 (2013) 284-294.

[16] A. Albrecht, A. Felk, I. Pichova, J.R. Naglik, M. Schaller, P. de Groot D. MacCallum, F.C. Odds, W. Schäfer, F. Klis, M. Monod, B. Hube, Glycosylphosphatidylinositol-anchored proteases of Candida albicans target proteins necessary for both cellular processes and host-pathogen interactions, J. Biol. Chem. 281 (2006) 688-694.

[17] S. Poltermann, A. Kunert, M. von der Heide, R. Eck, A. Hartmann, P.F. Zipfel, Gpm1p is a factor H-, FHL-1-, and plasminogen-binding surface protein of Candida albicans, J. Biol. Chem. 282 (2007) 37537-37544.

[18] S. Luo, A. Hartmann, H.M. Dahse, C. Skerka, P.F. Zipfel, Secreted pH-regulated antigen 1 of Candida albicans blocks activation and conversion of complement C3, J. Immunol. 185 (2010) 2164-2173.

[19] P.F. Zipfel, C. Skerka, J. Hellwage, S.T. Jokiranta, S. Meri, V. Brade, P. Kraiczy, M. Noris, G. Remuzzi, Factor H family proteins: on complement, microbes and human diseases, Biochem. Soc. Trans. 30 (2002) 971-978.

[20] M. Henriques, J. Azeredo, R. Oliveira, Candida albicans and Candida dubliniensis: comparison of biofilm formation in terms of biomass and activity, $\mathrm{Br}$. J. Biomed. Sci. 263 (2006) 5-11.

[21] E.H. Beachey, Bacterial adherence: adhesin-receptor interactions mediating the attachment of bacteria to mucosal surfaces, J. Infect. Dis. 143 (1981) $325-345$.

[22] M.K. Hostetter, Adhesins and ligands involved in the interaction of Candida spp. with epithelial and endothelial surfaces, Clin. Microbiol. Rev. 7 (1994) 29-42.

[23] V. Jimenez-Lucho, V. Ginsburg, H.C. Krivan, Cryptococcus neoformans, Candida albicans, and other fungi bind specifically to the glycosphingolipid lactosylceramide (Gal beta $1-4 \mathrm{Glc}$ beta $1-1 \mathrm{Cer}$ ), a possible adhesion receptor for yeasts, Infect. Immun. 58 (1990) 2085-2090.

[24] L. Yu, K.K. Lee, H.B. Sheth, P. Lane-Bell, G. Srivastava, O. Hindsgaul W. Paranchych, R.S. Hodges, R.T. Irvin, Fimbria-mediated adherence of Candida albicans to glycosphingolipid receptors on human buccal epithelial cells, Infect. Immun. 62 (1994) 2843-2848.

[25] D. Brassart, A. Woltz, M. Golliard, J.R. Neeser, In vitro inhibition of adhesion of Candida albicans clinical isolates to human buccal epithelial cells by Fuc alpha 1--2Gal beta-bearing complex carbohydrates, Infect. Immun. 59 (1991) 1605-1613.

[26] I.A. Critchley, L.J. Douglas, Isolation and partial characterization of an adhesin from Candida albicans, J. Gen. Microbiol. 133 (1987) 629-636.

[27] R. Autar, A.S. Khan, M. Schad, J. Hacker, R.M.J. Liskamp, R.J. Pieters, Adhesion inhibition of F1C-fimbriated Escherichia coli and Pseudomonas aeruginosa PAK and PAO by multivalent carbohydrate ligands, Chembiochem 4 (2003) 1317-1325.

[28] Y.M. Chabre, R. Roy, Multivalent glycoconjugate syntheses and applications using aromatic scaffolds, Chem. Soc. Rev. 42 (2013) 4657-4708.

[29] R.R. Kale, H. Mukundan, D.N. Price, J.F. Harris, D.M. Lewallen, B.I. Swanson, J.G. Schmidt, S.S. Iyer, Detection of intact influenza viruses using biotinylated biantennary S-sialosides, J. Am. Chem. Soc. 130 (2008) 8169-8171.
[30] D.M. Hatch, A.A. Weiss, R.R. Kale, S.S. Iyer, Biotinylated bi- and tetraantennary glycoconjugates for Escherichia coli detection, Chembiochem 9 (2008) 2433-2442.

[31] R. Roy, P. Murphy, H.J. Gabius, Multivalent carbohydrate-lectin Interactions: how synthetic chemistry enables insights into nanometric recognition, Molecules 21 (2016) 629-665.

[32] V.K. Tiwari, B.B. Mishra, K.B. Mishra, N. Mishra, A.S. Singh, X. Chen, Cu-catalyzed click reaction in carbohydrate chemistry, Chem. Rev. 116 (2016) 3086-3240.

[33] A. Karmakar, M.F.C. Guedes da Silva, S. Hazra, A.J.L. Pombeiro, Zinc amidoisophthalate complexes and their catalytic application in the diastereoselective Henry reaction, New J. Chem. 39 (2015) 3004-3014.

[34] F.D. Tropper, F.O. Andersson, S. Braun, R. Roy, Phase transfer catalysis as a general and stereoselective entry into glycosyl azides from glycosyl halides, Synthesis 1992 (1992) 618-620.

[35] C.O. Kappe, E. Van der Eycken, Click chemistry under non-classical reaction conditions, Chem. Soc. Rev. 39 (2010) 1280-1290.

[36] D. Poulain, Candida albicans, plasticity and pathogenesis, Crit. Rev. Microbiol. 41 (2015) 208-217.

[37] C. Collins-Lech, J. Kalbfleisch, T. Franson, P. Sohnle, Inhibition by sugars of Candida albicans adherence to human buccal mucosal cells and corneocytes in vitro, Infect. Immun. 46 (1984) 831-834.

[38] J. Sobel, P. Myers, D. Kaye, M. Levison, Adherence of Candida albicans to human vaginal and buccal epithelial cells, J. Infect. Dis. 143 (1981) 76-82.

[39] M. Foldvari, M.R. Jaafari, J. Radhi, D. Segal, Efficacy of the antiadhesin octyl O(2-acetamido-2-deoxy- $\beta$-D-galactopyranosyl)-(1-4)-2-O-propyl- $\beta$-D-galactopyranoside (Fimbrigal-P) in a rat oral candidiasis model, Antimicrob. Agents Chemother. 49 (2005) 2887-2894.

[40] F.S. Ielasi, M. Alioscha-Perez, D. Donohue, S. Claes, H. Sahli, D. Schols, R.G. Willaert, Lectin-glycan interaction network-based ildentification of host receptors of microbial pathogenic adhesins, mBio 7 (2016), https://doi.org/ 10.1128/mBio.01224-16.

[41] C. Palomo, J.M. Aizpurua, E. Balentova, I. Azcune, J.I. Santos, J. Jimenez-Barbero, F.J. Canada, J.I. Miranda, "Click" saccharide/ $\beta$-lactam hybrids for lectin inhibition, Org. Lett. 10 (2008) 2227-2230.

[42] S. Lamande-Langle, C. Collet, R. Hensienne, C. Vala, F. Chretien, Y. Chapleur, A. Mohamadi, P. Lacolley, V. Regnault, 'Click' glycosylation of peptides through cysteine propargylation and CuAAC, Bioorg. Med. Chem. 22 (2014) 6672-6683.

[43] M.T. Blazquez-Sanchez, F. Marcelo, M.d.C. Fernandez-Alonso, R. del VillarGuerra, A. Samadi, F.J. Canada, J. Jimenez-Barbero, C. Vicent, D- and LMannose-containing glyco-oligoamides show distinct recognition properties when interacting with DNA, Eur. J. Org Chem. 2015 (2015) 6180-6193.

[44] S.B. Salunke, N.S. Babu, C.T. Chen, Iron (III) chloride as an efficient catalyst for stereoselective synthesis of glycosyl azides and a cocatalyst with $\mathrm{Cu}(0)$ for the subsequent click chemistry, Chem. Commun. 47 (2011) 10440-10442.

[45] J.P. Chinta, C.P. Rao, Triazole linked lower rim glycosyl appended 1,3-calix[4] arene conjugates: synthesis, characterization, and their interaction with jacalin, Carbohydr. Res. 369 (2013) 58-62.

[46] D. Giguere, R. Patnam, M.A. Bellefleur, C. St-Pierre, S. Sato, R. Roy, Carbohydrate triazoles and isoxazoles as inhibitors of galectins- 1 and -3 , Chem. Commun. 22 (2006) 2379-2381.

[47] V. Haridas, Y.K. Sharma, S. Sahu, R.P. Verma, S. Sadanandan, B.G. Kacheshwar, Designer peptide dendrimers using click reaction, Tetrahedron 67 (2011) 1873-1884.

[48] C.H. Hsu, S. Park, D.E. Mortenson, B.L. Foley, X. Wang, R.J. Woods, D.A. Case, E.T. Powers, C.H. Wong, H.J. Dyson, J.W. Kelly, The dependence of carbohydrate-aromatic interaction strengths on the structure of the carbohydrate, J. Am. Chem. Soc. 138 (2016) 7636-7648. 